IFPRI Discussion Paper 01413

January 2015

\title{
Value Chains and Nutrition
}

A Framework to Support the Identification, Design, and

Evaluation of Interventions

\author{
Aulo Gelli \\ Corinna Hawkes \\ Jason Donovan \\ Jody Harris \\ Summer Allen \\ Alan de Brauw \\ Spencer Henson \\ Nancy Johnson \\ James Garrett \\ David Ryckembusch
}

Poverty, Health, and Nutrition Division

Markets, Trade and Institutions Division

CGIAR Research Program on Agriculture for Nutrition and Health 


\section{INTERNATIONAL FOOD POLICY RESEARCH INSTITUTE}

The International Food Policy Research Institute (IFPRI), established in 1975, provides evidence-based policy solutions to sustainably end hunger and malnutrition and reduce poverty. The Institute conducts research, communicates results, optimizes partnerships, and builds capacity to ensure sustainable food production, promote healthy food systems, improve markets and trade, transform agriculture, build resilience, and strengthen institutions and governance. Gender is considered in all of the Institute's work. IFPRI collaborates with partners around the world, including development implementers, public institutions, the private sector, and farmers' organizations, to ensure that local, national, regional, and global food policies are based on evidence. IFPRI is a member of the CGIAR Consortium.

\section{AUTHORS}

Aulo Gelli (a.gelli@cgiar.org) is a senior scientist in the Poverty, Health, and Nutrition Division of the International Food Policy Research Institute (IFPRI), Washington, DC.

Corinna Hawkes is head of Policy and Public Affairs at the World Cancer Research Fund International, London.

Jason Donovan is a marketing specialist for the World Agroforestry Center, Lima, Peru.

Jody Harris is a senior research analyst in the Poverty, Health, and Nutrition Division of IFPRI, London.

Summer Allen is a research coordinator in the Markets, Trade and Institutions Division of IFPRI, Washington, DC.

Alan de Brauw is a senior research fellow in the Markets, Trade and Institutions Division of IFPRI, Washington, DC.

Spencer Henson is a professor in the Food, Agriculture and Resource Economics Department at the University of Guelph, Ontario, Canada.

Nancy Johnson is a senior research fellow for the CGIAR Research Program on Agriculture for Nutrition and Health at, IFPRI, St. Paul, MN, US.

James Garrett is a senior research fellow in the Poverty, Health, and Nutrition Division of IFPRI, Rome.

David Ryckembusch is a senior programme adviser for the World Food Programme, Rome.

Notices

1. IFPRI Discussion Papers contain preliminary material and research results and are circulated in order to stimulate discussion and critical comment. They have not been subject to a formal external review via IFPRI's Publications Review Committee. Any opinions stated herein are those of the author(s) and are not necessarily representative of or endorsed by the International Food Policy Research Institute.

2. The boundaries and names shown and the designations used on the map(s) herein do not imply official endorsement or acceptance by the International Food Policy Research Institute (IFPRI) or its partners and contributors.

Copyright 2015 International Food Policy Research Institute. All rights reserved. Sections of this material may be reproduced for personal and not-for-profit use without the express written permission of but with acknowledgment to IFPRI. To reproduce the material contained herein for profit or commercial use requires express written permission. To obtain permission, contact the Communications Division at ifpri-copyright@cgiar.org. 


\section{Contents}

Abstract $\quad$ V

Acknowledgments $\quad$ vi

1. Introduction 1

2. Value Chains and Nutrition 4

3. A Framework for Assessing the Potential Impact of Value Chains for Nutrition Interventions

4. Identifying and Designing Value Chains for Nutrition Interventions 15

5. Indicators for Evaluating Value Chain for Nutrition Interventions 21

6. Themes for Further Research 28

Appendix A: Examples of the Design of Value Chain for Nutrition Projects 33

Appendix B: Supplementary Figures

References 


\section{Tables}

4.1 Examples of VCN objectives and interventions within the different typologies 20

5.1 Summary of indicators for the demand-side pathway for VCN interventions 23

5.2 Examples of indicators for the supply-side pathway for VCN interventions 25

5.3 Examples of indicators for measuring nutrition value-addition along the value chain 27

6.1 Summary of key themes for future research 28

A.1 Key activities by type of hub 43

Figures

1.1 Prevalence of stunting in children aged $0-5$ years and GDP per person 2

2.1 Stylized example of a food supply chain $\quad 5$

3.1 Simplified impact theory of supply and demand side value chain interventions 10

4.1 Typologies characterizing value chain interventions based on the supply and demand of nutritious foods

A.1 Stylized food value chain for ANEP project with potential impacts across different target groups 37

A.2 Stylized food value chain for the AVDRC project with potential impacts across different target groups

A.3 Stylized food value chain for LDB dairy project with potential impacts across different target groups

A.4 Stylized food value chain for HGSF with potential impacts across different target groups 51

B.1 Examples of entry points across value chains for enhanced nutrition 55

B.2 Example of agriculture and nutrition pathways 56 


\begin{abstract}
Income growth alone cannot solve the problem of malnutrition and may in fact create problems linked to overweight and obesity. The challenge from the nutrition perspective is how to sustainably improve the quality of diets, as well as other health-nutrition related behaviours, across different populations and age groups? In nutrition debates in developing countries there is growing interest in the capacity of the private sector to contribute to improved nutrition outcomes. Discussions have incorporated thinking around value chain frameworks, which emerged in the late 1990s to help development actors design interventions that responded to the needs of the private sector and contributed to development outcomes. Value chain approaches can provide useful frameworks to examine the food system and the potential to achieve improved nutritional outcomes by leveraging market-based systems. However, understanding the links between value chains, the overall business environment in which they operate, and nutrition among targeted populations is complex, involving actors and activities working across agriculture, health and nutrition, and very little evidence exists on the potential or the trade-offs involved.

In this paper we explore how a value chain framework can inform the design of interventions for achieving improved nutrition. Conceptually, there are three main channels for value chains to improve nutrition: (1) through increased consumption of nutritious foods (a demand side pathway); or (2) through increased incomes from value chain transactions (a supply side pathway) or (3) through increased nutrition value-addition in the chain transactions. These three pathways are interlinked and involve complex dynamics that are not straightforward to understand.

We also highlight how these pathways are context specific, and introduce typologies based on supply and demand profile of the specific value chain. Where adequate supply and demand for a specific food exists, interventions would focus on optimising the efficiency and flow of nutrition added-value along the chain. Where demand is constrained or overconsumption is a problem, interventions would work primarily to change consumption patterns, either directly (for example, food transfers) or indirectly (such as, social marketing) shaping market demand. Where supply is constrained, interventions would focus on enhancing supply-side capacity by improving production practices, organising production and post-harvest activities to increase efficiency, and facilitating the expansion of market opportunities. We conclude with a summary of key research areas in this emerging field.
\end{abstract}

Keywords: nutrition, diets, value chain, agriculture 


\section{ACKNOWLEDGMENTS}

This paper was written by Aulo Gelli with contributions from Corinna Hawkes, Jason Donovan, Jody Harris, Summer Allen, Alan de Brauw, Spencer Henson, Nancy Johnson, James Garrett, and David Ryckembusch. Amanda Wyatt provided inputs on the workshop and developed the East-Africa Dairy Development (EADD) case study. Expert input and feedback was provided on the project by Marie Ruel, John McDermott, Maximo Torero, Josephine Kiamba, Anna Herforth, and Laurian Unnevehr. We would also like to thank the participants of the Agriculture for Nutrition and Health (A4NH) workshop on value chains for nutrition held at IFPRI in March 2014. 


\section{INTRODUCTION}

The recent Lancet Series on Maternal and Child Nutrition estimated that the aggregate global burden of undernutrition caused ${ }^{1}$ more than 3 million child deaths per year and stunting prevalence in children under five affected at least 165 million children (Black et al. 2013). Micronutrient deficiencies, including zinc and vitamin A, contribute to increased child and maternal mortality, while deficiencies of iron and iodine, together with stunting, also impair the development of infants and young children. In parallel, globally, an estimated 43 million children under five years of age were overweight, a 54 percent increase from an estimated 28 million in 1990. The increasing rates of childhood overweight and obesity are likely to have important impacts on adult obesity, diabetes, and other noncommunicable diseases. The prevalence of overweight and obesity doubled since 1980 (from 6 to 12 percent globally), and the increase has accelerated (Stevens et al. 2012).

Cross-country evidence indicates that income growth is associated with decreasing maternal and child undernutrition (Haddad et al. 2003, Ruel and Alderman2013). Using cross-sectional data, it has been estimated that a 10 percent increase in gross domestic product (GDP) is associated with a 6 percent decrease in stunting and a 4 percent decrease in women underweight (Figure 1.1). On the other hand, income growth also has unintended negative consequences; the same data indicate that a 10 percent increase in GDP is associated with a 7 percent increase in overweight and obesity in women. The coexistence of over- and undernutrition in low- and middle-income countries has been captured in the literature as the result of the "nutrition transition," which involves rapidly changing diets (increased consumption of calories, saturated fat, and sugars) coupled with reductions in physical activity and increases in sedentary lifestyle (Popkin et al. 2013). Analysis of the drivers of these trends is an active area of research. Particular attention has been drawn to the role of the changing food system and its influence on energy intake, although many other environmental and individual factors are involved (Swinburn et al. 2011). It is clear that economic growth alone cannot resolve the problem of undernutrition and that it may in fact create other problems, such as overweight and obesity, and increased risks of associated chronic diseases.

\footnotetext{
${ }^{1}$ It is important to note that this is a causal estimate based on comparative risk assessment methods including joint distributions of stunting, wasting, fetal growth restriction, deficiencies of vitamin A and zinc, and suboptimum breastfeeding.
} 
Figure 1.1 Prevalence of stunting in children aged 0-5 years and GDP per person

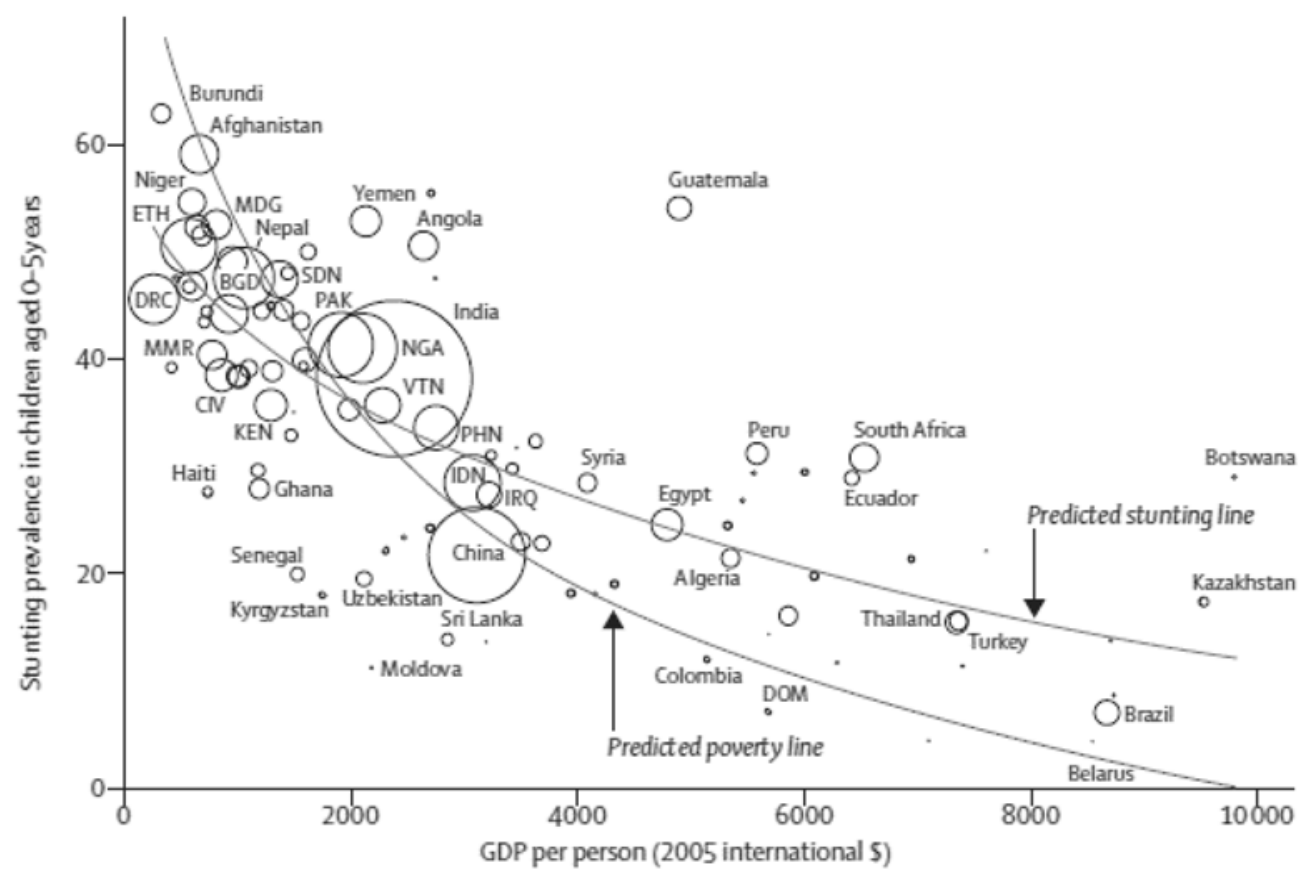

Source: Ruel and Alderman (2013).

Note: GDP = gross domestic product. The size of the circles represents estimates of the population of stunted children aged $0-5$.

One way of tackling these multiple challenges involves promoting food-based approaches to increase access to high-quality diets (Arimond et al. 2011). In low-income settings, households typically subsist on monotonous staple-based diets; they lack access to nutritious foods, such as fruits, vegetables, animal source foods, or wild foods of high nutrient content. Lack of diet diversity is strongly associated with inadequate intake and risks of deficiencies of essential micronutrients (Ruel 2003; Arimond et al. 2010). Economic constraints, lack of knowledge and information, and related preferences (lack of demand for nutritious foods) are critical factors that limit poor populations' consumption of such foods. Agricultural production is just one factor in the consumption and availability of nutrients. Food is stored, distributed, processed, marketed, prepared, and consumed in a range of ways that affect the access, acceptability, and nutritional quality of foods for the consumer. Recent reviews of the contribution of agriculture in improving nutrition conclude that although agricultural programs have immense potential to improve nutrition, this potential is yet to be unleashed (Masset et al. 2011; Ruel and Alderman 2013). Current evidence suggests that limitations in the design and implementation of agriculture interventions, as well as a lack of clarity in terms of nutrition goals and interventions, are partly responsible for the weak evidence base. Even more important, the lack of rigor in most of the existing impact evaluations prevents any clear conclusions regarding the contribution of agriculture in improving nutrition (Ruel and Alderman 2013).

Researchers and program implementers have recently recognized that value chain concepts can be useful in designing strategies to achieve nutrition goals (Hawkes and Ruel 2011; Ruel and Alderman 2013). Central to this approach is identifying opportunities where chain actors benefit from the marketing of agricultural products with higher nutritional value. However, value chain development focuses on efficiency and economic returns among value chain transactions, and the nutritional content of commodities is generally not considered. The potential for value chains to enhance nutrition through interventions is clear, but so far now there has been little documented experience. 
This paper aims to develop a framework based on program-theory ${ }^{2}$ concepts to support the identification, design, and evaluation of value chains for nutrition interventions. The work draws upon existing frameworks (Henson et al. 2013; Hawkes and Ruel 2011) and is complementary to ongoing efforts to understand impact pathways for agriculture, nutrition, and health (Webb 2013; Turner et al. 2013; Gillespie et al. 2012).

In this paper we define the value chain for nutrition approach as the process of developing a strategy that addresses a set of nutrition problems through interventions within specific value chains. The starting point in this approach centers on diagnostics aimed at linking a set of nutrition problems in target populations to possible constraints in the supply and demand of specific foods that can then be addressed by interventions. Such a strategy includes a hierarchy of goals and objectives, where the high-level goals center on the health and nutrition of consumers, reflecting the end result that is intended. The objectives can involve changes in agricultural production, processing, or any other related food chain activity that is relevant to the context and value chain constraint in question. Breaking down the complex scope into different components involves a series of steps, including diagnostics of the problem, followed by the development of possible solutions (including the identification of entry points for interventions across one or more value chains), design and implementation, and evaluation and learning.

In the rest of the paper we describe some of the details that this approach entails. We begin by reviewing the emerging literature on value chains and nutrition; we then build on a synthesis of case studies on the design of value chain for nutrition interventions to capture the impact pathways linking value chain activities to potential effects on nutrition; we then propose a set of diagnostics and typologies to support the identification and design of interventions; and we then draw on existing standards and references to propose a set of indicators to measure the performance of interventions. We conclude with a summary of the main research themes in this multidisciplinary field.

\footnotetext{
${ }^{2}$ Following Rossi et al. 2005, we focus on impact theory, or the causal chain linking activities to their results in target groups.
} 


\section{VALUE CHAINS AND NUTRITION}

In this section we provide an overview of the main literature on value chains and nutrition. This includes a discussion of the type of research that this entails, the actors involved, and the potential linkages between them that could lead to improved nutrition outcomes.

\section{What Is a Value Chain?}

A food value chain is a form of food supply chain (Figure 2.1), or the series of processes and actors that take a food from its production to consumption and disposal as waste (Hawkes and Ruel 2011). In a value chain, the emphasis is on the value (usually economic) accrued (and lost) for chain actors at different steps in the chain, and the value produced through the functioning of the whole chain as an interactive unit. A value chain is commodity specific, and as such involves only one particular food that is relevant within a diet.

Since the mid-1990s, value chain concepts have featured prominently in rural development discourse (Altenburg 2007; Humphrey and Navas-Alemán 2010; Stoian et al. 2012). As an approach to rural development, the value chain concept focuses on improving the commercial relations between two or more actors along a chain, with the expectation that such improvements yield economic benefits for those involved, including smallholders. It is also important to distinguish between value chains as a concept and value chain analysis. Value chain analysis can be thought of as a method of analysis and also as a programmatic framework for the design and implementation of interventions. The value chain approach challenges governments and civil society to achieve development goals by looking beyond individual actors, such as smallholders or cooperatives, and look at the links between them. This enables the development of interventions to better identify common problems among actors in the chain and generate solutions with win-win outcomes that address trade-offs across these outcomes. Improved chain relations and overall chain performance could yield tangible benefits in terms of economic returns and, potentially, poverty reduction. Medium and large-scale businesses can also potentially be involved as active partners in value chain development, providing opportunities to achieve outcomes at greater scale, with possibly increased impact and sustainability.

Value chain development has become a principal element of the poverty-reduction strategies of development agencies, donors, and governments. Interest in value chain development stems largely from an increased awareness among development organizations that success in increasingly complex agrifood markets often requires stronger collaboration among value chain actors, including producers, processors, and retailers (Hobbs, Conney, and Fulton 2000; Humphrey and Memedovic 2006). Other important factors that have spurred interest in value chain development include growing urban demand for addedvalue foods in developing countries, more stringent quality and food safety standards by governments and private firms, the growth of niche markets (for example, organic and fair trade), and concern over the scarcity of agricultural raw materials. Small-scale producers have a comparative advantage in crops that require high labor inputs, such as coffee, dairy, and horticulture, and rapid growth in demand for such products has been considered an opportunity to combine economic growth and poverty-reduction goals (Bacon 2005; Weinberger and Lumpkin 2007).

Value chain concepts and interventions have historically not considered nutrition, either in terms of improved nutrition of smallholder producers or of consumers in peri-urban and urban settings; rather, the focus has been mainly on increased income for smallholders and other stakeholders along the value chain (Hawkes 2013). Because value chains play a key role in determining food availability, affordability, quality, and acceptability, they provide opportunities to promote nutrition (Hawkes and Ruel 2011). The key is to identify opportunities where value chain actors benefit from supplying the market with agricultural products of higher nutritional value. Value chain development, however, has rarely focused attention on consumers-consumers are simply considered as purchasers driving the ultimate source of demand. In this light, value chain concepts and frameworks could be enriched by a stronger consumer focus, and in particular, a focus on consumer nutrition and health. 
Figure 2.1 Stylized example of a food supply chain
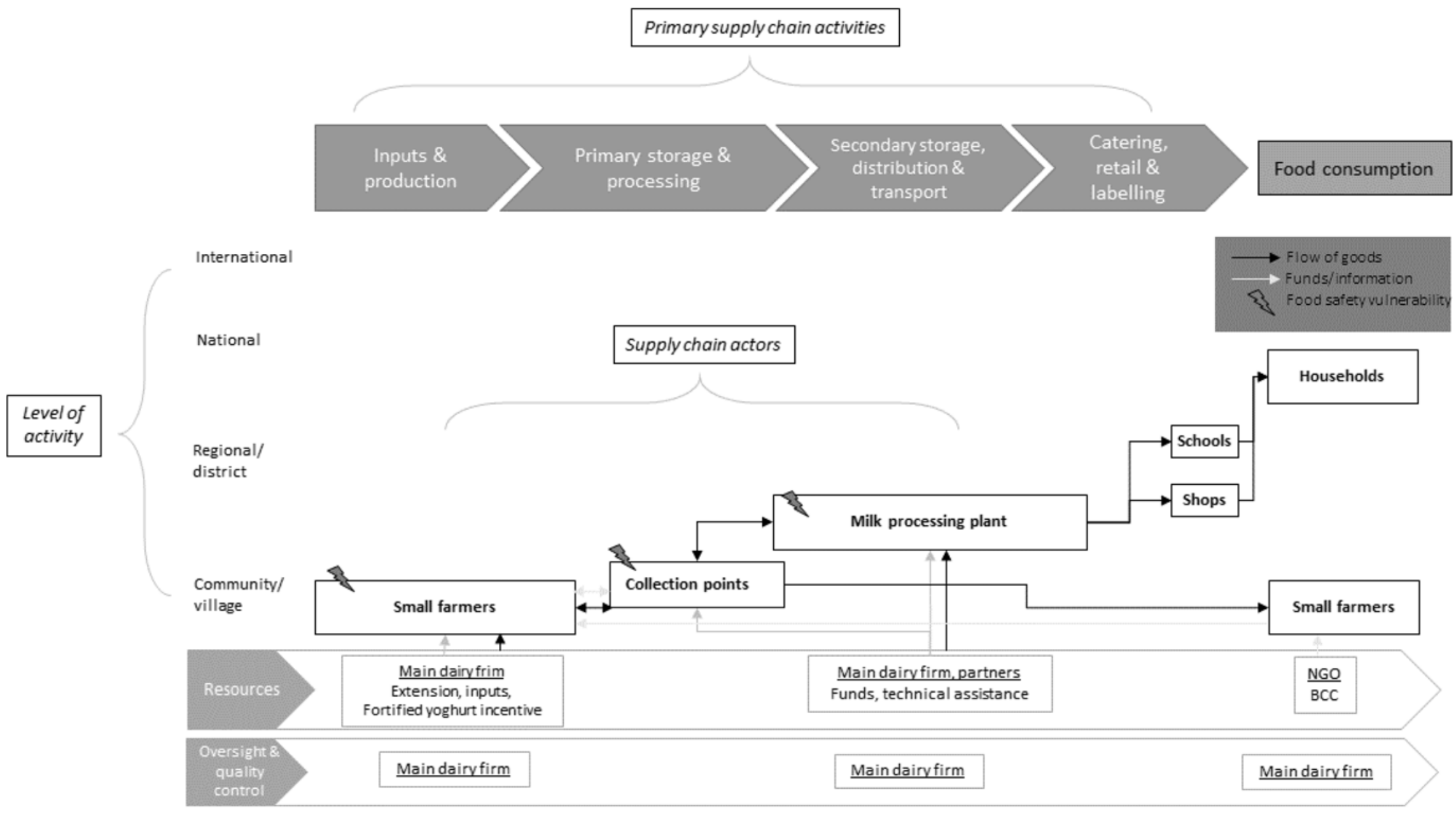

Source: Adapted from Kretschmer et al. (2014).

Note: $\quad \mathrm{NGO}=$ nongovernmental organization; $\mathrm{BCC}=$ behavior change campaign . 


\section{Existing Evidence Linking Value Chains to Nutrition}

There is very little empirical evidence on the role of value chains in improving nutrition. The emerging literature in this field, however, advocates the opportunity for linking value chains to nutrition, and includes case studies and frameworks that begin to develop these links explicitly. Generally, the literature recognizes that agricultural and food policy is more likely to positively affect nutritional outcomes when the structure and functioning of markets is taken into account. Thus, just as researchers have viewed value chains through the lens of sustainable resource management or rural poverty, they can view value chains through the lens of nutrition. Hawkes et al. (2012) draw attention to the limited reach of agricultural policy in influencing nutrition outcomes when a systems approach is not applied. They argue that the food industry can respond to changes in agricultural policy in several ways, such as changing ingredients, using different processing technologies, or supplying specific agricultural products in different forms to markets. If improved nutrition is sought through changes in agricultural policy, then an understanding of market actors and their incentives (disincentives) and capacities (limitations) to help generate healthier food products becomes important. Gereffi et al. (2009) examine the role of large, multinational firms in determining the nutritional performance of value chains. In particular, they describe the considerable influence of certain retailers and processors on the availability, safety, quality, and nutritional value of food and suggest that improved nutritional outcomes are possible by concentrating attention on the actions of these firms. Others have focused on the business environment in which food is sold. For example, Maestre et al. (2014) describe how low levels of consumer awareness, the inability of firms to signal quality to consumers, and restricted distribution outlets effectively limit the ability of the private sector to respond with nutrient-dense products for mass consumption.

Recent case study evidence demonstrates how value chain concepts are being applied to understand marketing systems and their influence on nutritional outcomes. Studies in high-income countries tend to focus on diet diversity and overnutrition. Gereffi et al. (2009) examine the value chains for chicken and tomatoes in the United States, and argue that the powerful firms, such as supermarkets and large-scale processors, significantly shape the availability and type of products consumed. In both cases, productivity and efficiency increased in the chain, and prices for the respective outputs of the chains dropped over time. However, gains in availability and affordability were countered with reduced variety and increased access to processed foods. Looking at the value chain for canned peaches in Australia, Hattersley (2012) also highlighted the role of powerful firms in bringing about positive outcomes for high-end consumers through the manufacture of canned peaches with minimal processing. However, the study offered inconclusive results regarding the nutrition outcomes for consumers given the overall ambiguity involving processed fruits and diet quality.

Importantly, to date most of the debate on markets, business, and value chains has focused on multinational enterprises. There is a need to question how relevant this is for the poor. Thus, the focus needs to shift to the markets in which they engage (and thus the businesses and value chains that are most relevant to the poor). In this context, it is important to recognize the ways in which food markets are transforming in developing countries. The few case studies that exist on value chains and nutrition in the context of low-income countries focus mostly on undernutrition. Maestre et al. (2014) and Robinson et al. (2014b) apply a value chain perspective to understand the potential for actors along chains for ready-touse therapeutic food (RUTF) to expand their sales in Tanzania and Nigeria, respectively. In both cases, expansion of RUTF sales was limited by weak demand, the inability to signal nutritional quality of the products to consumers, and limited access to high-quality inputs, among other factors. These cases point out the need for major changes in the business environment for the private sector to deliver greater impacts on nutrition. In this context, solutions can also involve public-private collaborations to enhance chain efficiency while providing nutritious foods to poor populations, as demonstrated by the recent work on supply chains for school meals (Gelli et al. 2013; De Carvalho et al. 2012). Padulosi et al. (2013) also apply a value chain approach to the promotion of neglected and underutilized foods in the Andes. By tackling the supply and demand constraints for these particular crops, the uptake of sustainable and 
improved production practices was promoted, resulting in positive nutrition and health outcomes for poor, rural populations.

A project led by the Institute of Development Studies (IDS) on Strengthening Agrifood Value Chains for Nutrition aims to identify opportunities for improving private-sector involvement in food systems, and analyzes strategies to overcome the barriers that prevent nutrient-rich foods from reaching people suffering from undernutrition in Ghana, Nigeria, and Tanzania. Anim-Somuah et al. (2013a) examine the constraints that inhibit private-sector involvement in value chains of nutritious foods, including complementary foods, using multiple qualitative methods in Ghana. Drawing on the value chain analysis of groundnut and complementary foods, this study highlighted how ubiquitous aflatoxin contamination, the inability to signal nutritional value, and a lack of traceability of foods were important areas for policy intervention (Anim-Somuah et al. 2013b). In addition, though a range of complementary foods was available on the market that met nutrition and safety standards, they were generally not affordable to the poor, highlighting once again the potential role of the public sector to promote pro-poor outcomes. Using the same framework in Nigeria, Robinson et al. (2014a) examined policy options for reducing undernutrition through market-based approaches. The study identified five major market constraints in the provision of nutrient-dense foods that were beyond the control of individual businesses, including low awareness of nutrition among low-income populations; absence of quality-signaling mechanisms; poorly organized supply chains for nutrient-dense foods, resulting in higher prices and low quality; expensive distribution networks for low-income populations; and complex business environments alongside low levels of trust in institutions.

\section{Lessons Learned So Far}

Frameworks that incorporate value chains and nutrition are evolving, and the literature identifies several important starting points (Hawkes and Ruel 2011; Gómez and Ricketts 2013; Gomez et al., 2011; Henson and Humphrey 2013; Anim-Somuah et al. 2013a; 2013b; Padulosi et al. 2013). Nutrition-sensitive value chains, or value chains for nutrition (VCN), can be seen as a framework to first identify and then alleviate constraints, or market failures, in terms of the supply and demand for nutritious foods. VCN involve and explicitly link activities from stakeholders at different levels across agriculture, nutrition, and health sectors within an integrated system, including the following.

- Because value chains include activities from food production, postharvest through to consumers, they provide useful lenses for characterizing the broader food system and identifying entry points for policies and interventions to improve nutrition.

- Conceptually, economic value can be examined alongside other added-value, including nutrition but also other potential effects along the value chain, such as environmental sustainability.

- A broader perspective of a value chain includes the public sector and the various NGOs and private-service providers that support value chain actors, providing a window to intervene in areas where markets may not yet exist or function adequately.

- VCN also provide a framework where overnutrition, undernutrition, and diets more broadly are characteristics of stakeholders influenced both directly and indirectly by the chain activities.

However, these types of frameworks also have their challenges. The scope of VCN interventions is both extremely broad and context specific. Clearly, no one size fits all, and understanding and dealing with the breadth of scope and heterogeneity is not straightforward. Critically, nutrition results from the quality of the overall diet, not just from the nutrient content of an individual food. In value chains, the focus is generally commodity specific, rather than on how to integrate multiple chains to contribute to an enhanced quality of diet (Henson 2013). There may be offsetting impacts such that, if one value chain works better and consumption of the associated food increases, consumption of other foods may decline. 
VCN interventions are therefore more likely to have success in filling gaps in the diet rather than improving overall nutritional status, though the evidence on these effects is still lacking.

The concept and issue of value chain governance is also critical and is a key tenet of the concept of value chains and of value chain analysis. It is important to understand the broader macro-level context, or enabling environment, within which food chains operate, including policy and governance; political and economic context; culture, gender, and equity; and climate and environment (Hawkes et al. 2012).

\section{Understanding the Impact Pathways Linking Value Chain Activities to Nutrition}

In summary, though there has been considerable interest in linking value chains to nutrition, important evidence gaps limit the understanding of the feasibility of this approach. Of particular relevance in terms of evidence generation is the lack of clarity in terms of the pathways linking value chain activities to nutrition. This includes understanding the requirements that need to be achieved in order for value chains to bring about increased consumption of nutritious food. In turn, there is a need to understand what constraints prevent these requirements from being met and the interventions that are likely to be most effective in alleviating these constraints. These issues are all highly context specific. The conceptualization of the program impact pathways as presented in this paper provides the basis for theory-based evaluations ${ }^{3}$ and is an important platform to support the evidence-generation process in this emerging, multidisciplinary field.

\footnotetext{
${ }^{3}$ See Rossi et al. 2004 and Habicht et al. 1999 for more details on theory-based evaluations.
} 


\section{A FRAMEWORK FOR ASSESSING THE POTENTIAL IMPACT OF VALUE CHAINS FOR NUTRITION INTERVENTIONS}

In this section we outline some of the pathways through which VCN interventions can be expected to operate (Caldes and Ahmed 2004; Ahmed and Sharma 2007; Sumberg and Sabates-Wheeler 2011; Masset and Gelli 2013). This analysis provides the basis for the identification and design of interventions along value chains for nutritious foods. We conceptualize the impacts of value chain interventions on nutrition operating through three main channels involving the dynamics of demand and supply for nutritious foods:

- VCN interventions can increase the demand on the market by promoting consumption of nutritious foods. This can involve direct transfers to consumers (such as school meals), through public procurement, and/or more indirect channels, including behavior change and social marketing that influence preferences and household choices. This channel will be explored in more detail in the subsection entitled, "Impact Pathways through Changes in Food Demand."

- Interventions can enhance the supply of nutritious foods by reducing costs, increasing output, and economic returns along the value chain. This more "traditional" type of value chain channel, with a focus on nutritious foods, is described in the "Impact Pathways through Changes in Food Supply subsection.”

- Interventions can influence chain efficiency, affecting food availability, quality, and affordability as well as other elements of the food environment that can enhance nutrition outcomes. This includes the dynamics of four value chain properties involved in "nutrition" value-addition, including nutrient density, ${ }^{4}$ food safety risk (contamination), quantity, and price. These processes and characteristics will be explored in more detail in the subsection, "Mediators of Potential Impact."

These channels are interlinked and include important feedback effects and trade-offs (Figure 3.1). As a result of these dynamics, we theorize that there are three main impact domains for VCN interventions, (1) nutrition and health, (2) agricultural production, and (3) enterprise development for stakeholders involved in value-addition along the chain. In this framework, the value chain is the set of processes through which the impacts in these domains are achieved, highlighting also that the nutrition content and food safety of a particular food can be enhanced or diminished at key points in the value chain.

${ }^{4}$ Nutrient density lacks a formal definition but generally refers to the ratio of nutrient content to the total energy of a given food (Drewnowski 2005). 
Figure 3.1 Simplified impact theory of supply and demand side value chain interventions

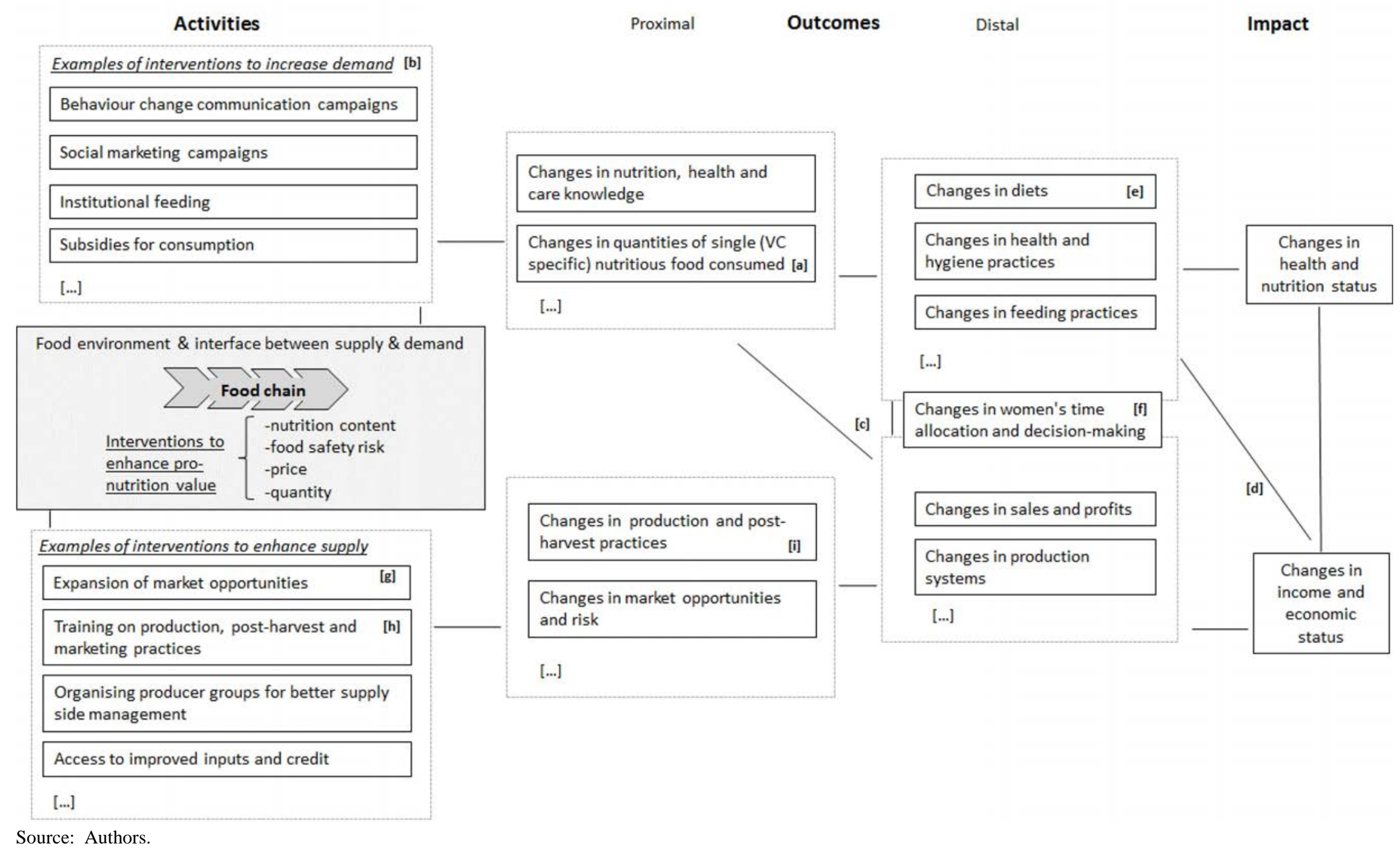

Source: Authors. 


\section{Impact Pathways through Changes in Food Demand}

Where nutrition diagnostics have identified a demand constraint (such as underconsumption of, or low demand for, nutritious foods), value chain interventions can be used to alleviate this constraint. Interventions that influence the demand for nutritious foods may have an impact on nutrition if they improve diets via the increased consumption of these foods. Increased consumption of nutritious foods (1) can be achieved through a combination of direct transfers (such as transfer of nutritious food through school meals, vouchers, or subsidies for consumption) and/or indirect market channels involving behavior change campaigns or social marketing that promotes the consumption of, or willingness to pay for, the nutritious food (2). The nutritious food may be produced by the same households consuming the food (3) or may be purchased on the market (4). The availability (quantity available on the market), affordability (price), and quality (including nutrition content and food safety) are key issues that influence consumption at the interface between the value chain and the food environment. The intake of the nutritious food complements the consumption of other foods in the diet [(5)], which may be self-produced or purchased on the market. The nutritious food may be shared within the household or consumed by only a few household members. It may also substitute for other foods that would have been normally consumed or for foods with similar properties. This point highlights the need to examine changes in overall diets and not just assess consumption of one food. All these effects are mediated to some degree by women's role in the household, time allocation, and decisionmaking [6]. Improved diets, when accompanied by adequate feeding, health, and hygiene practices can then contribute to improved health and nutrition.

The impact of interventions on the nutrition and health status of consumers will depend on the nature of the dietary changes with the target populations. In particular, changes in individual-level dietary diversity have been found to be strongly associated with micronutrient adequacy of diets for women (Arimond et al. 2010) and micronutrient density adequacy of diets in children (FANTA 2007). Addressing micronutrient deficiencies can improve a range of health, nutrition, and developmental outcomes in infants and young children, particularly if implemented alongside other demand-side value chain interventions like behavior change on health and nutrition practices (Bhutta et al. 2013).

Because the emphasis of these interventions is on influencing overall dietary intake, this framework can be considered relevant to both under- and overnutrition contexts. Where obesity is a result of the overconsumption of particular foods, the focus of demand-side value chain interventions will be to actively address this imbalance by reducing the consumption of the unhealthy foods while providing healthier alternatives. School-based behavior change campaigns, for example, have been used to promote consumption of fruits and vegetables (Van Cauwenberghe et al. 2010), and reduce the intake of processed foods and beverages. Behavior change campaigns can also be used to influence knowledge, attitudes, and practices that are relevant to obesity, such as physical activity and the development of healthy eating habits.

Increasing the demand for nutritious foods would also lead to expanding marketing opportunities for producers (step [g]). This increased demand can play an important role in terms of stimulating agricultural production, particularly for smallholders who face market access constraints, especially as increased demand may be regular and predictable, providing a relatively stable revenue channel and seen as a low-risk venture for producers. The extent of the effect of the increased demand on prices will depend on the level of market integration. The potential effects on producers are captured in the next subsection. Increases in demand could also be linked to the provision of information regarding nutrient quality and food safety risks of the specific food in question. These two issues will be explored in more detail in "Mediators of Potential Impact." 


\section{Impact Pathways through Changes in Food Supply}

This is the standard value chain pathway: Value chain interventions can target producers and firms that often face multiple constraints in responding to the needs of actors further downstream in the chain. From a supply perspective, VCN interventions can target overall production by increasing overall yields or efficiencies through input provisions or training on improved management practices. VCN interventions can also influence the basket of products that are produced, supporting the production of higher-value crops and/or more nutritious crops through seed provision, educational campaigns, or market forces. The targeting of particular crops has to be undertaken in the context of the substitution between crops for production and consumption and the long-term impacts on both income and nutrition at multiple scales (from the household and village levels to regional or national levels).

The impact of interventions on agricultural output and prices will depend on the supply and demand for that particular food. The change in overall demand for a nutritious food that results from increased consumption of nutritious foods will depend on the size and structure of the market as well as on substitution among the basket of goods consumed at the household level. When the supply of nutritious foods is limited, interventions can be aimed at alleviating supply constraints. This can be achieved, for example, through the adoption [h] of advanced production technologies, or mechanisms to reduce input costs so production of those crops is relatively more profitable. The supply of particular crops can also be promoted through institutional reforms. The provision of insurance, access to credit, and land titling, for example, can reduce risk some for producers.

In broad terms, if supply-side constraints are not alleviated, additional demand will cause increased local prices. The extent of this effect will depend on the level of market integration. Increased prices should create additional opportunities for producers. If producers were able to increase their production of nutritious foods in response [i], then the overall price effect would be dampened. However, these relationships are complicated given that producers are often consumers as well as producers, and some are also net food buyers rather than net food sellers throughout the year. The effect of price increases for particular products on smallholders who are net food buyers throughout the year is not always straightforward, and depends on the basket of goods they produce and how easily they can transition components of their production to follow prices. In addition to the increased supply of nutritious foods, increased production and incomes for smallholders could mean that some income feeds back into dietary decisions, further increasing consumption and demand for nutritious foods [d].

In summary, VCN interventions can have an effect on prices and food production. They can also reduce market risk through improved links with buyers and more reliable demand. Although changes in expectations will take some time, the reduction in risk can influence a number of household coping strategies (such as savings and investments). Coupled with increased production and sales volumes, these changes can result in increased farm-level profits as well as more long-term decisionmaking and investments, and eventually increase incomes that can then lead to improved nutrition. Several of these relationships are complex and measuring intermediate results is important in order to better understand the market structure and environment, and the overall impact on both producers and consumers.

\section{Enterprise Development along the Value Chain}

The previous sections outlined some of the direct and indirect effects of VCN interventions on agriculture, nutrition, and health status of potential target groups. There is also a range of other potential effects on stakeholders involved in the postharvest value chain activities. Traditionally, in value chain analysis the main emphasis has been on capturing economic returns for value chain actors. The definition of value is based on the willingness to pay for what a firm provides, and "value" is usually measured in terms of total revenue, a function of price and quantities sold (Porter 1985). The supply-side channel summarized above reflects this notion of value. Moreover, the concepts presented there on alleviating constraints in the demand and supply of nutritious foods can be extended to activities further along the chain, where the focus shifts to stakeholders, or firms, involved in value-addition. In broad terms, a similar results chain can still apply. Interventions would look to alleviate constraints in supply and 
demand, and strengthen market channels, while increasing production volumes and reducing transaction costs and risk; this would lead to increased efficiency and profits, and in time lead to improved incomes.

\section{Mediators of Potential Impact}

The value chain activities provide the market links between the demand and supply pathways mapped in Figure 3.1. The performance of the market transactions along the value chain affects commercial relations and firm profits. Value chain performance also mediates the effects on nutrient intake and diets that can potentially lead to improved nutrition. Four characteristics of value chain performance are particularly relevant in determining the extent to which these effects can occur, including the quantity (or supply volumes), price, and quality (including both nutritional content and food safety) of a relevant food. These four value chain characteristics also affect major elements of the food environment, including food availability, affordability, and acceptability. In this framework, both the nutritional content and the food safety of a particular food can be enhanced or diminished at key points along the value chain.

\section{Improving Nutrition and Food Safety along a Value Chain}

Conceptually, this is equivalent to internalizing these "pro-nutrition" characteristics within an extended notion of value along the supply chain. However, for "nutrition added-value" to factor into the value chain transactions, reliable information on both nutrition quality/content and safety risk must be transmitted along the chain, and prices would reflect a premium for both nutritional content and food safety. In practice this is often not the case, particularly in low-income settings. Because nutritional value includes properties that are akin to those of credence goods, there is no incentive to pay for quality unless there is some form of visible, third-part activity that may be undertaken publicly (such as information campaigns) or privately (such as consumer reporting) (Minot 2014).

Many highly nutritious foods, including meat, milk, fish, and vegetables, are the riskiest in terms of food safety. Because of their perishability, these risks often grow as value chains lengthen and become more complex. For perishable, nutritious foods, informal value chains generally supply the majority of these foods, especially to poorer households, and are likely to continue to do so in the near term. Where government systems to support food safety are emerging and consumers' choices may be limited by income and information, the most important incentives to safe production-private demand and effective government regulation-are lacking.

Measurements of this pro-nutrition value, added at key points in the chain, can be used to identify bottlenecks as well as opportunities to enhance nutrition and the transmission of information. Examples of relevant interventions that enhance nutritional value include fortification, enrichment, processing multiple foods into more nutritious products, food safety and detoxification, labeling, and sensitization. A number of recent activities have been undertaken to potentially enhance the flow of nutrition information along the chain, including the development of nutrient profiles for processed foods (WHO 2013) and the development of metrics and benchmarks to evaluate the cost-efficiency of interventions in food supply chains (Gelli et al. 2011; Ryckembusch et al. 2012). These activities, though, also imply costs for actors along the value chain in enhancing or maintaining the nutritional value of food and communicating this in a reliable manner to consumers. How this can be achieved when the value chain also has to keep prices affordable to the poor is an important area for future research.

It is also important to examine a number of other crosscutting issues that influence the value chain pathways, including policy, gender, and coordination across sectors, among others. The influence of these issues on chain performance is comprehensive and as such they should be mainstreamed within this type of analysis. 


\section{Gender}

There is growing evidence that gender discrimination is a fundamental driver of poor nutritional outcomes (Quisumbing et al. 2014). Women play important roles in production and value-addition and agriculture has the potential to empower them to make better food-, health-, and care-related decisions for themselves and their families. For example, it is likely that the introduction of different agricultural practices, particularly in areas where many farmers are women, will impact time allocation and labor in ways that might negatively affect childcare practices. Any agricultural development that expands and formalizes markets should be careful to avoid inadvertently disempowering women by adding to their time burden and/or reducing their control over income. Understanding and monitoring these feedback effects will be important to ensure, at a minimum, a do no harm approach to interventions.

\section{Coordination}

The efficiency of value chain activities is influenced by the coordination of stakeholders along the chain. In VCN, coordination involves activities and stakeholders across traditional disciplines, including agriculture and health, and often coordination between government entities and the private sector. Although there is considerable variation in the degree of intensity, most case studies in the literature (Hawkes and Ruel 2011, Annex A) include an explicit focus on coordination activities. Understanding the need for coordination along the value chain and among agriculture and nutrition interests, and how coordination must take place in practice, are important areas for future research (Garrett and Natalicchio 2012; Harris and Drimie 2012). 


\section{IDENTIFYING AND DESIGNING VALUE CHAINS FOR NUTRITION INTERVENTIONS}

In this section we draw on the analysis of the VCN impact pathways to develop the details behind the intent to systematically make value chains more relevant to nutrition. We define a "value chain for nutrition approach" as the process of developing a strategy to address nutrition problems through interventions that alleviate constraints in demand and supply in specific value chains. The high-level goals of this strategy center on the health and nutrition of consumers, reflecting the end result that is intended. The specific objectives will relate to the main constraints that are involved (see "Defining Intervention Objectives Based on the Context and the Intended Effects"). The structure of the strategy is based on the pathways through which VCN interventions can be expected to improve nutrition, including three main channels linking the demand and supply for nutritious foods:

- On the demand side, the main pathway to nutrition involves improving diets through increased consumption of nutritious foods. This channel is most relevant where diagnostics have identified deficiencies in the diets of target populations.

- On the supply side, the main pathway to nutrition is through improved economic returns, and involves the traditional value chain development framework, reducing costs, increasing output, sales, and profits along the value chain, leading to improved incomes.

- A third pathway involves interventions within the value chain, which in this framework is the interface between the demand and the supply pathways. Improved chain efficiency (where output is not economic, but also involves measures of nutrition and food safety) will influence the food environment, including food availability, quality, and affordability that in turn can lead to improved nutrition.

We develop this approach further through a series of steps that are outlined in the following sections, including diagnostics of the problem and the context, followed by the development of possible solutions (including the identification of entry points for interventions across one or more value chains), design and implementation, and evaluation and learning.

\section{Diagnostics}

The aims of the diagnostics are to link a set of nutrition problems in target populations to possible constraints in the supply and demand of specific foods that can then be addressed by interventions. In this framework, these diagnostics can be broken down into a series of five key steps, building on that described by Timmer et al. (1983) and more recently by WHO (2013). ${ }^{5}$ It is important to note that some of the data requirements involved are complex and it is essential to be pragmatic in terms of the detail and intensity of the analysis involved. Drawing on existing datasets will be particularly relevant.

\section{Step 1: Identify the Nutrition Problem to Be Addressed}

This step provides evidence on the factors that are contributing to nutrition problems and the extent of their contribution, some of which may be dietary, while others may not. The starting point involves characterizing the nutritional problem, including nutritional status, dietary patterns, feeding practices, and other indicators related to nutritional outcomes and their determinants (Black et al.2013). The assessment also broadly identifies existing gendered constraints and opportunities in terms of access, intake, and utilization of nutritious foods, including nutrition knowledge, preferences, attitudes, and practices. Both undernutrition and overnutrition perspectives should be covered where the nutrition transition is relevant. Potential target groups would also be identified for intervention.

\footnotetext{
${ }^{5}$ A recent example of this type of diagnostic was undertaken in Ghana (Anim-Somuah et al. 2013a; 2013b).
} 


\section{Step 2: Analyze the Macro-Level Food Systems Context}

This step includes examining the macro-level context, or the enabling environment, and characterizing secular and seasonal trends in food systems. The range of dimensions involved includes policy and governance, political environment, sociocultural norms and practices, and climatic and other environmental conditions (see FAO 2013). This step also includes an analysis of food balance sheets to capture secular trends in terms of food supply. A detailed analysis of these dimensions is beyond the scope of this work and remains an important area for future research.

\section{Step 3: Characterize Diets, Identifying Constraints and Relative Contributions of Key Foods}

This step involves examining data on diets and consumption patterns, comparing actual intake to the requirements and recommended intake for specific target groups, generally defined by age and sex. Understanding the dietary constraints in a specific location involves the development of typologies of diets, including food baskets or bundles based on location-specific dietary data and dietary guidelines, which are converted into equivalent nutritional bundles using food composition tables. The different bundles can be compared to the dietary requirements for specific groups. The analysis would also need to be disaggregated by nutrient type to enable the identification of nutrition deficiencies or excesses (Ferguson et al. 2004). This type of analysis provides data on the relative contributions and prioritization of different commodities in terms of their contribution to overall diets and nutritional intake, as well as an understanding of the gaps that can be filled and the recommended diets to meet those needs. Costing these diet-based food bundles using market prices provides insights on the costs of an actual diet and provides a basis for cost per nutrient metrics against which the cost-efficiency of interventions can later be benchmarked (Maillot et al. 2008). Because collecting dietary data is resource intensive, it is important to identify existing data sources as well as gaps that would require further investments.

This step can also be used to identify foods that are (1) nutrition-poor or contaminated (through loss of nutrition value or increased food safety risks across the chain), (2) underconsumed, (3) "missing" (such as new varieties), and (4) overconsumed (such as foods that are being consumed but are not healthy).

\section{Step 4: Examine Nutrition and Food Safety Value-Addition}

This step identifies the constraints in supply and demand of nutritious foods. In addition, it identifies potential entry points for intervention along relevant chains. Characterizing diets allows for the identification of opportunities for improving diet quality by enhancing the supply and demand of specific foods, including fruits and vegetables, biofortified foods, and nutritious but often traditionally neglected and underutilized crop species (such as pulses, grains, and other indigenous foods).

Once commodities have been prioritized in the context of the total diet, the focus shifts to undertaking supply and value chain analyses for the target foods. In this step, the value chain analysis is broadened to include assessments of "nutrition value," including nutrient density and food safety, plus measures of food quantity, prices, and margins at key points along the chain. In this framework, both nutrition content and food safety of a particular food can be enhanced or diminished at key points along the value chain.

This analysis involves identifying market failures and/or constraints in supply and demand. For example, smallholder farmers may not grow optimal amounts of nutritious foods from an economic perspective because they lack access to inputs or output markets. This supply gap may also be related to the inability to ensure against the risks of producing such foods or because of health impacts from consuming unsafe foods due to inadequate regulations or enforcement of food safety regulations. There is a range of other factors that can impact the supply of these foods. The gender of the producer may contribute to different constraints to producing nutritious foods. For example, women producers may not be inclined to supply the market if they are not able to control the income from crop sales. Traders and 
processors in the informal sector may not have access to information and technology to maintain the quality and safety of perishable foods. While advances are needed in this regard, it must be balanced, because initiatives to meet food safety standards for access to export markets might lead to inappropriate regulation in domestic markets that is ineffective in terms of improving food safety and may harm the poor.

Finally, each value chain should be contextualized within the broader food system to identity constraints in terms of the "enabling environment" that may influence value chain performance.

\section{Step 5: Prioritize Intervention Options}

This step provides the evidence to prioritize and justify investments in specific interventions. Once the constraints and opportunities have been identified within specific value chains, including identifying different target groups for intervention, the emphasis shifts toward guiding investment decisions, including the development of criteria to prioritize the range of interventions identified in step 4. This can include the development of business and investment case models that simulate the potential costs, effects, and returns on investment for scaling-up the interventions. These models will need to consider short-term effects as well as long-term effects on these sectors and the feedback loops that exist between them.

\section{Identifying and Designing Relevant Value Chain Interventions}

Once the diagnostics are complete and a target crop or food has been identified, the focus shifts to designing interventions aimed at alleviating the constraints on demand and supply in a specific value chain. The range of possible interventions is very broad, including research and development, direct public and/or private investment, and government policy and regulation, among others. In some cases, interventions along a value chain will be relatively straightforward. This may be the case, for example, when solutions involve providing nutritional information on a given food that is already widely produced and consumed, or fortifying selected foods. In other cases, interventions along a value chain will be relatively intensive (requiring long-term investments to stimulate changes in production, processing, and marketing). The most intensive interventions will be required when major gaps or barriers exist in both the supply of and the demand for a specific food. This situation may emerge, for example, when a new product with considerable nutritional value is introduced to consumers, but adequate sources of supply have yet to evolve, as in the case of ready-to-use complementary foods. This case could also apply to specific pro-poor interventions in both supply and demand, where the poorest smallholders are targeted to supply foods for public distribution programs.

The variation in intensity of investments on the supply and demand sides can be used to characterize a set of typologies for specific value chain interventions. An example is shown in Figure 4.1, along with the implications for the design of value chain interventions. In this figure, the vertical axis represents the variation in existing demand (high or low demand for foods). The horizontal axis represents the differences in the production and postharvest supply chain for these foods. Here we use the term "consistent supply" to refer to the condition where there is no major supply-side constraint. 
Figure 4.1 Typologies characterizing value chain interventions based on the supply and demand of nutritious foods

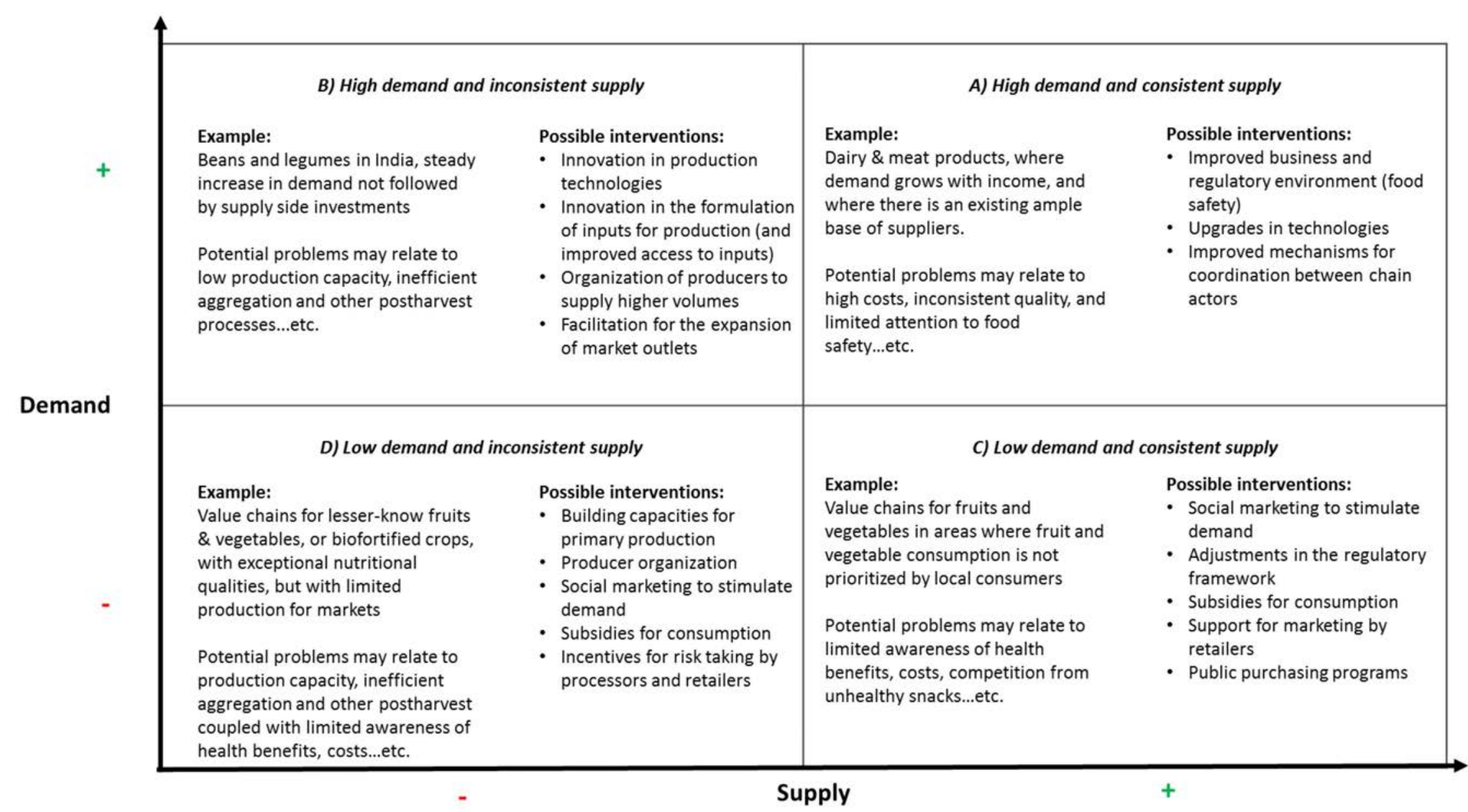

Source: Authors. 


\section{Interventions to Enhance Pro-Nutrition Added-Value}

Where demand and supply exist for a nutritious food, interventions would focus on optimizing transactions in the existing chain and enhancing the nutrition added-value along the chain (quadrant A). This could be achieved by reducing the overall costs per nutrient output through, for example, fortification, by combining different foods, or by reducing contamination and food safety risks. Interventions in this quadrant can target specific points in the value chain where efficiencies can be introduced, or where nutritional or food safety leakages exist. Alternatively, interventions in this quadrant may look to provide information at key points in the chain or enhance overall flows of information along the chain. Interventions involving the provision of quality assurance and improved regulatory frameworks are also relevant in this quadrant and can lead to important gains in efficiency. This is demonstrated in the case of the school meals program in Chile, where improved tendering regulations increased transparency of financial flows and reduced transaction costs considerably (Epstein et al. 2004). The main immediate results of these types of interventions include increased efficiency (such as enhanced nutrient content or reduced contamination per unit price of food) or increased knowledge and willingness to pay for a nutritious and safe food. The catering/fortification home-grown school feeding (HGSF) implementation model (Appendix A) is an example of an intervention in this quadrant.

\section{Interventions That Enhance the Supply of Nutritious Food}

In some contexts, ample demand for a specific nutritious food from consumers may exist but the supply side is constrained (quadrant B). In this case, interventions would mainly aim to relax these constraints by, for example, improving the organization of production or introducing new production technologies to enhance the supply. The more immediate intended effects of interventions involve changes in production and postharvest practices, risks from climate and markets, prices, and price stability. The dairy value chain projects (see Appendix A) are examples of these types of interventions.

\section{Interventions That Enhance the Demand for Nutritious Food}

Where the context includes value chains for foods that are widely produced but are not consumed by the target populations (quadrant C), interventions would strive to enhance the demand for the nutritious foods through social marketing campaigns or public procurement programs like school meals. Behavior change campaigns can combine the promotion of both the consumption of specific foods and healthy behaviors and feeding practices. The immediate effects of interventions in this quadrant center on changes in consumption, health, and nutrition practices and women's time allocation and role in household decisionmaking. All the projects summarized in Appendix A, except for the East Africa Dairy Development, included some degree of nutrition messaging aimed at increasing the demand for more nutritious foods. HGSF also provides direct food transfers to the target populations to increase the demand for that particular food on the market.

\section{Introducing New Types of Nutritious Foods}

When introducing a new food within the target population, interventions would aim to develop a functioning and table source of supply while at the same time investing in demand promotion for the food (quadrant D). This quadrant captures interventions that generally require the most intensive investments on both the production and the consumption side. The introduction of biofortified crops (such as orangefleshed sweet potato in Appendix A) or new fortified products are examples of interventions in this quadrant. 


\section{Defining Intervention Objectives Based on the Context and the Intended Effects}

The typology introduced in the preceding section leads to insights on the possible objectives for value chain interventions based on both the context and the potential sequencing of intended effects summarized in the program theory in Section 3. For example, where interventions look to enhance supply (quadrants B and D), by addressing agricultural production, postharvest, and marketing constraints, the resulting short-term effects would involve changes in production and postharvest practices, as well as changes in market opportunities and risk. Where the intent behind interventions is to increase the consumption of nutritious food and the associated demand for the nutritious foods on the market (quadrants $\mathrm{C}$ and $\mathrm{D}$ ), the intended short-term effects include changes in nutrition, health, and care knowledge; changes in women's time allocation and decisionmaking roles; and increases in the quantities of the specific nutritious food consumed. Interventions across quadrants, if effective, would allow the value chain to evolve toward quadrant A, where the intent focuses on "pro-nutrition" value-addition along the chain. including:

This approach can be used to develop a set of context-driven objectives for interventions,

1. Promoting consumption of nutritious food (quadrants C and D): Interventions target multiple stakeholders, primarily consumers (but also producers for own consumption), and aim to improve diets by increasing consumption of nutritious foods and enhancing nutrition knowledge, attitudes, and practices.

2. Enhancing the supply of nutritious food (quadrants B and C): Interventions mainly target producers and small- and medium-scale enterprises involved in the supply of nutritious foods, and aim to increase production and sales by improving agricultural practices, increasing market opportunities, and reducing risk from the market (in terms of price volatility) and the environment.

3. Increasing the nutrition added-value along the nutritious food chain (quadrant A): Interventions would target the more aggregate value chain actors such as processors, and the regulatory environment, aiming to enhance the nutrition added-value and efficiency along the chain.

Relevant interventions can then be framed within each objective and tailored to the specific context and target groups, as summarized in Table 4.1, building on examples presented in FAO (2013).

Table 4.1 Examples of VCN objectives and interventions within the different typologies

\begin{tabular}{|c|c|c|c|}
\hline Typology & Objectives & Target groups & Interventions \\
\hline$C, D$ & $\begin{array}{l}\text { Promoting consumption of } \\
\text { nutritious food }\end{array}$ & Consumers, producers & $\begin{array}{l}\text { Nutrition and health messaging } \\
\text { Product labeling } \\
\text { Nutrition education }\end{array}$ \\
\hline$B, D$ & $\begin{array}{l}\text { Enhancing supply of } \\
\text { nutritious food }\end{array}$ & Producers & $\begin{array}{l}\text { Income transfer, food assistance } \\
\text { Training on production, postharvest, and marketing } \\
\text { practices } \\
\text { Access to technology, inputs, and credit } \\
\text { Organising producer groups } \\
\text { Expansion of market outlets } \\
\text { Nutrition and health messaging }\end{array}$ \\
\hline$A$ & $\begin{array}{l}\text { Increasing pro-nutrition } \\
\text { added-value }\end{array}$ & $\begin{array}{l}\text { Processors, producers, } \\
\text { consumers }\end{array}$ & $\begin{array}{l}\text { Food safety, detoxification } \\
\text { Fortification, reformulation, combination } \\
\text { Reducing costs } \\
\text { Product labeling } \\
\text { Nutrition and health messaging }\end{array}$ \\
\hline
\end{tabular}

Source: Authors. 


\section{INDICATORS FOR EVALUATING VALUE CHAIN FOR NUTRITION INTERVENTIONS}

This section introduces potential indicators that provide information on whether expected changes are occurring based on the impact pathways and typologies developed in the preceding sections.

\section{Measuring Changes on the Demand-Side Pathway}

\section{Proximal Outcome Indicators}

The most direct indicator that a VCN intervention is achieving the desired outcome centers on changes in the quantities of nutritious food consumed. Consumption of the target food in the target population(s) should be measured using dietary recall methods (Gibson and Ferguson 1999). If an intervention is promoting a specific nutrient (for example, biofortified foods or foods known to be high in a certain nutrient), it will be important to assess target nutrient consumption by using food composition tables and programs that calculate nutrient content of foods in the overall diet (Ferguson et al. 2004). Women are key determinants of nutrition during the first 1,000 days, both in terms of their own nutrition and health during pregnancy and usually in terms of childcare and feeding in the first two years. Different aspects of women's empowerment are therefore crucial for nutrition and are likely to be affected by VCN programs. In particular, women's time use (especially between agricultural activities and childcare activities), maternal energy expenditure (particularly on agricultural tasks during pregnancy), and decisionmaking power (regarding the trade-offs between agricultural and childcare decisions) link agriculture and nutrition. These aspects can be measured using different modules of the Women's Empowerment in Agriculture Index (Alkire et al 2012). Women's knowledge, particularly around nutrition, health, and child feeding and care, can also be changed by VCN projects, and should therefore be measured. There is, however, no defined tool or method for this other than general survey techniques asking contextappropriate questions.

\section{Distal Outcome Indicators}

Infant and young child feeding (IYCF) is a key issue in determining nutritional status, and has a defined set of indicators for measurement of both breastfeeding and complementary feeding (WHO 2010). Dietary diversity, a measure of nutrient adequacy in the diet and therefore of overall diet quality, is also an important distal outcome, and VCN interventions should either measure it as a key outcome or monitor displacement of other foods in the diet by foods promoted by the VCN intervention. There are two validated Individual Dietary Diversity Score (IDDS) measures covering the 1,000-day period, one for children aged six to 23 months (WHO 2010) and one for women (FAO 2011). Dietary diversity is measured as the intake of discrete food groups over the previous 24 hours (seven food groups for children, 16 for women). Within a population group, dietary diversity is then measured as the mean number of food groups consumed, and among children the proportion achieving minimum dietary diversity (consuming four or more food groups the previous day). Some VCN interventions may choose to more fully evaluate effects on diets and intake, and would therefore measure nutrient adequacy in the diet directly rather than by using the proxy IDDS. Measuring nutrient adequacy of the diet is generally resource intensive and requires a dietary recall to assess which foods a person has eaten; use of food composition tables or programs to calculate the nutrient composition of those foods in total; and comparison to the nutrient recommendations for the population group (age and sex) to which that person belongs (Gibson and Ferguson 2008). 
In addition to dietary diversity, meal frequency and composition are key elements of dietary adequacy for optimal IYCF. VCN interventions may impact these elements positively (through increased access to food, or knowledge of nutritious foods) or negatively (requiring more of a woman's time for agricultural production or food purchasing/preparation), so it is necessary to measure all the possible effects of VCN interventions on dietary adequacy. The Minimum Acceptable Diet (MAD) indicator comprises minimum dietary and minimum meal frequency for a child's age, along with appropriate milk feeds (breast or non-breast milk) (WHO 2010), and is calculated for children aged six to 23 months. Because VCN interventions may positively or negatively affect IYCF through increased knowledge or decreased care time as noted previously, they might also affect other health and hygiene practices through similar mechanisms. Again, there is no single defined tool or method for assessing health and hygiene practices, other than asking context-appropriate questions.

\section{Impact Indicators}

Three indicators of child nutritional status are used to assess levels of undernutrition: stunting, wasting, and underweight. Each is measured in children under the age of five and expressed as a Z-score (the deviation from the mean of a reference population). The primary measure used in nutrition programs is stunting, based on the height-for-age Z-score (HAZ). An HAZ expresses a child's height for a given age, and a Z-score of less than -2 denotes stunting, or growth faltering as a result of chronic undernutrition. Stunting may be measured in a VCN intervention if the program is also addressing (or linked to other programs that address) the "health" and "care" determinants of undernutrition; otherwise, VCN interventions should focus on assessing dietary outcomes. Stunting is measured using standard anthropometry procedures, and population-level results for different age groups zero to five years are compared to a standardized reference population (WHO Multicenter Growth Reference Study Group 2006). In older children, adolescents, and adults, body mass index (BMI) is used instead of Z-scores (WHO 1995); in adults, a BMI of less than 18.5 denotes underweight, and a BMI of more than 25 denotes overweight. Some VCN interventions may aim to increase levels of specific nutrients in the diet, and therefore may want to measure impact in the body. Various biomarkers for different nutrients exist, generally measured in the blood (iron and vitamin A) or urine (iodine) (Hedrick et al. 2012). Because biological processes are complex, it is generally not enough just to measure the specific biomarker, so other information must also be collected, such as markers of immune function. Given the inherent complexity of measuring these impacts over time and the considerations needed to collect this type of data, those wishing to measure nutrient biomarkers in their research should work with an expert in this field. The indicators along the food demand-side pathways in Figure 3.1 are summarized in Table 5.1. 
Table 5.1 Summary of indicators for the demand-side pathway for VCN interventions

\begin{tabular}{|c|c|c|c|c|}
\hline Indicators & & Population group & Tools and methods & Reference \\
\hline \multicolumn{5}{|l|}{ Impact } \\
\hline \multicolumn{5}{|c|}{ Changes in nutrition status } \\
\hline & Stunting, wasting, underweight & Children $0-59 \mathrm{~m}$ & Anthropometry and statistical analysis & WHO Multicentre Growth Reference Study Group 2006 \\
\hline & BMI & $>59 \mathrm{~m}$-adult & Anthropometry and statistical analysis & WHO 1995 \\
\hline & Biomarkers & All ages & Blood and urine analysis & Various \\
\hline \multicolumn{5}{|c|}{ Changes in health } \\
\hline & Agriculture-related disease incidence & All ages & & \\
\hline \multicolumn{5}{|c|}{ Distal outcomes } \\
\hline \multicolumn{5}{|c|}{ Changes in consumption (diet, multiple foods) } \\
\hline & \multirow{2}{*}{ Dietary diversity } & Children $6-23 \mathrm{~m}$ & Individual Dietary Diversity Score & WHO 2006 \\
\hline & & Women & Individual Dietary Diversity Score & FAO 2011 \\
\hline & Nutrient adequacy & All ages & $\begin{array}{l}\text { Dietary recall + food composition tables + } \\
\text { nutrient recommendations }\end{array}$ & \\
\hline \multicolumn{5}{|c|}{ Changes in feeding practices } \\
\hline & Dietary adequacy & Children $6-23 \mathrm{~m}$ & Minimum Acceptable Diet & WHO 2006 \\
\hline \multicolumn{5}{|c|}{ Changes in health and hygiene practices } \\
\hline & Practices & Women & No defined tool or method & $\mathrm{N} / \mathrm{A}$ \\
\hline \multicolumn{5}{|c|}{ Proximal outcomes } \\
\hline \multicolumn{5}{|c|}{ Changes in quantities of nutrious food consumed } \\
\hline & Target food consumption & All ages & Dietary recall & \\
\hline & Target nutrient consumption & All ages & Dietary recall + food composition tables & \\
\hline \multicolumn{5}{|c|}{ Changes in nutrition, health and care knowledge } \\
\hline & Knowledge & Women & No defined tool or method & $\mathrm{N} / \mathrm{A}$ \\
\hline \multicolumn{5}{|c|}{ Changes in women's empowerment } \\
\hline & Women's time use & \multirow{3}{*}{ Women } & \multirow{3}{*}{$\begin{array}{l}\text { Women's Empowerment in Agriculture Index } \\
\text { (modules) }\end{array}$} & \multirow{3}{*}{ WEAI 2012} \\
\hline & Maternal energy expenditure & & & \\
\hline & Women's decisionmaking power & & & \\
\hline
\end{tabular}

Source: Authors. 


\section{Measuring Changes on the Supply-Side Pathway}

The indicators for the supply-side pathway in Figure 3.1 are summarized in Table 5.2. The structure of these is inherently different than the nutrition-related indicators because they are often reliant upon only one or two pieces of data. How these are calculated may vary and while seemingly straightforward, some of them prove difficult to capture accurately or consistently. For example, determining the members of an agricultural household is complicated by a variety of family structures and co-living arrangements as well as migration. In each context, these dynamics should be well understood before attempting to collect this type of data. What type of data is appropriate to collect from household members is also very context specific. Throughout these indicators, measurement error and associated data quality are important issues to consider. Farm area, used as the basis for which many inputs and outputs are analyzed, is subject to reporting bias (Carletto et al. 2013). In addition, it is common that farmers may not have good measurements of critical components used for monitoring production, including annual production (due to multiple harvests, especially for vegetables), labor (because it is often part time), or even of the land area planted in particular crops (due to intercropping or crop rotations). This makes comparison difficult and often additional data are needed to check for consistencies or measurement issues with these components. Examples of the difficulty in these measurements and strategies for helping to mitigate them have been documented (Diskin 1999). 
Table 5.2 Examples of indicators for the supply-side pathway for VCN interventions

\begin{tabular}{|c|c|c|c|c|}
\hline Impact & & Population Group & Indicators & Reference \\
\hline \multicolumn{5}{|c|}{ Changes in income/economic status } \\
\hline & Household net income & $\begin{array}{l}\text { all working members of } \\
\text { household }\end{array}$ & $\begin{array}{l}\text { on-farm income minus costs/rents, off-farm income (salaried or hourly), } \\
\text { transfers/other inflows }\end{array}$ & FAO 2011 \\
\hline & Opportunities & household & $\begin{array}{l}\text { diversity of production and off-farm opportunities; time available/use; } \\
\text { access to improved inputs and credit }\end{array}$ & \\
\hline & Risk & $\begin{array}{l}\text { producer groups; } \\
\text { local market }\end{array}$ & $\begin{array}{l}\text { price volatility (input and output prices); } \\
\text { risk-sharing through group formation; insurance/contracts }\end{array}$ & \\
\hline \multicolumn{5}{|c|}{ Distal Outcomes } \\
\hline \multicolumn{5}{|c|}{ Changes in sales and profits } \\
\hline & Profit from all products & household & $\begin{array}{l}\text { input costs and/or output prices; transaction costs; price and income } \\
\text { stability }\end{array}$ & \\
\hline & Market access & $\begin{array}{l}\text { household; } \\
\text { producer groups }\end{array}$ & $\begin{array}{l}\text { new opportunties, secure marketing arrangements; volumes sold; access to } \\
\text { high-value markets; lower transaction costs }\end{array}$ & \\
\hline & Market share & $\begin{array}{l}\text { household; } \\
\text { producer groups }\end{array}$ & $\begin{array}{l}\text { value-added processing (vertical integration); number of products meeting } \\
\text { some form of standard }\end{array}$ & EC 2009 \\
\hline \multicolumn{5}{|c|}{ Changes in production systems } \\
\hline & Supply of nutritious foods & household; village & $\begin{array}{l}\text { volumes produced; area planted; yields; share of nutritious foods and/or } \\
\text { high-value crops produced }\end{array}$ & \\
\hline & $\begin{array}{l}\text { Volume, quality and postharvest } \\
\text { losses }\end{array}$ & household & $\begin{array}{l}\text { quality produced; storage (amount, time stored, infrastructure); amount of } \\
\text { crop lost }\end{array}$ & Diskin 1999 \\
\hline \multicolumn{5}{|c|}{ Proximal Outcomes } \\
\hline \multicolumn{5}{|c|}{ Changes in production and postharvest practices } \\
\hline & $\begin{array}{l}\text { Knowledge of improved farming } \\
\text { practices }\end{array}$ & $\begin{array}{l}\text { household; } \\
\text { producer groups }\end{array}$ & knowledge of optimal input use etc.. & \\
\hline & Production practices & $\begin{array}{l}\text { household; } \\
\text { producer groups }\end{array}$ & $\begin{array}{l}\text { access to inputs (e.g. credit, fertilizers, extension), number of ha with } \\
\text { improved practices }\end{array}$ & WDI 2014; FAO 1999 (various) \\
\hline & Postharvest management & $\begin{array}{l}\text { household; producer } \\
\text { groups; village }\end{array}$ & number of storage facilities built; storage practices & Diskin 1999 \\
\hline \multicolumn{5}{|c|}{ Changes in market opportunities/risk } \\
\hline & $\begin{array}{l}\text { Knowledge of market opportunities } \\
\text { and prices }\end{array}$ & $\begin{array}{l}\text { household; } \\
\text { producer groups }\end{array}$ & prices (absolute and stability); contracts; available market information & EC 2009; various \\
\hline & $\begin{array}{l}\text { Responses to signals from market or } \\
\text { education }\end{array}$ & $\begin{array}{l}\text { household; } \\
\text { producer groups }\end{array}$ & crop mix planted (staples versus higher-value/nutritious products) & EC 2009 \\
\hline
\end{tabular}

Source: Authors.

Note: References provided are often contextual references (of which there are many) rather than measurement references. 


\section{Proximal Outcome Indicators}

In the short term, VCN interventions can enhance knowledge of improved farming practices, leading to changes in production practices that increase yields and/or efficiencies as well as changes in postharvest practices such as storage. These changes can be supported by some of the interventions mentioned earlier (such as educational campaigns on food safety and nutrition) as well as more direct interventions, such as the promotion of increased processing. Interventions can also involve enhanced marketing channels and improve knowledge of market opportunities (prices, volumes, and timing), leading to short-term production responses to these market signals (including changes in the crop mix planted). Interventions in VCN may also lead to improved access to inputs or input-related information, shifting household-level constraints and further supporting different practices at the farm level.

\section{Distal Outcome Indicators}

Changes in production practices and output could then result in increased marketed surplus, sales, and profits, as well as changes in farm-level production systems and a crop mix that favors higher value or more nutritious crops. As a result of the changes in postharvest practices, with time, there may be increased quality and less production lost. On a midterm time horizon, changes in marketing and market information may be seen and more of the market might be captured through vertical integration. Prices may become more stable and transaction costs can decrease. Higher value markets may be accessed and standards may be put in place to ensure quality, signal this quality to the consumers, and allow producers to capture premiums. Increased agri-enterprise opportunities may result.

\section{Impact Indicators}

In the longer term, the focus is on increasing overall income through increased production and sales. As mentioned previously, VCN interventions can impact incomes, economic status, and market structures, as well as create shifts in risk and opportunities. There can also be a shift in people's own production of nutritious foods (increase in supply). As described in "Impact Pathways through Changes in Food Supply," any increase in demand without a shift in supply could have negative effects on prices. Even with increased production of nutritious or higher quality foods, the relationship remains complex due to the fact that many rural households are net food buyers. Supply and demand interactions and corresponding effects at the household level are ultimately determined by larger market mechanisms that should be monitored when assessing potential impacts.

\section{Indicators for Measuring Performance and Value-Addition along the Chain}

A number of interrelated properties of value chain transactions are relevant in the context of nutrition, including the volumes or quantities of nutritious foods involved, the food quality (in terms of both nutrition content and safety), and prices. Other chain properties may also be desirable in the medium and longer term, including metrics for sustainability, for example, but these are beyond the scope of this work. A series of indicators, including nutrient profiles (WHO 2013b), can be developed based on these characteristics to benchmark and monitor performance at key points along the chain, from production to consumption (Table 5.3). Costs per unit of nutrient output, for example, has been used to benchmark supply chains for the delivery of alternative commodity baskets and nutrition content (Ryckembusch et al. 2012; Gelli et al. 2011; Bundy et al. 2009). 
Table 5.3 Examples of indicators for measuring nutrition value-addition along the value chain

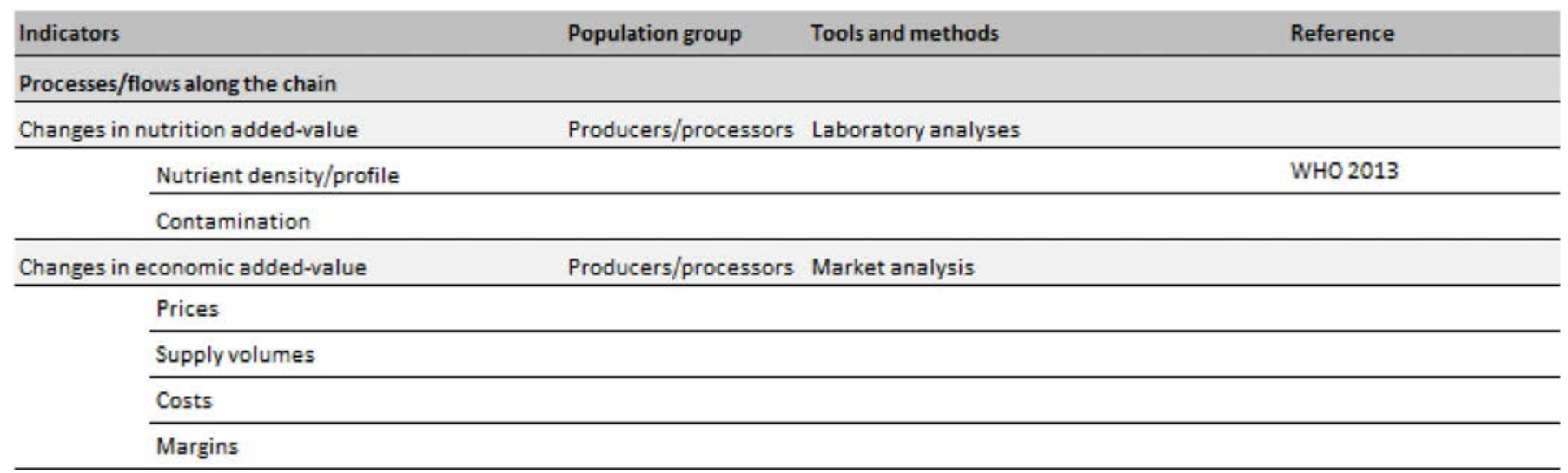

Source: Authors. 


\section{THEMES FOR FURTHER RESEARCH}

The concept of VCN is innovative and therefore little evidence currently underpins activities in this area. In this paper we provided an overview of the potential direct and indirect effects of value chain activities across agriculture, nutrition, and health. We proposed that the VCN approach aims to address a set of nutrition problems, with multiple objectives framed around alleviating constraints in specific value chains. We then outlined the key steps involved in further developing this approach from a multidisciplinary perspective, including considerations on diagnostics and intervention design. In this section, we conclude by building on the content generated in this paper to overview future research themes in this emerging multidisciplinary field (as summarized in Table 6.1).

\section{Table 6.1 Summary of key themes for future research}

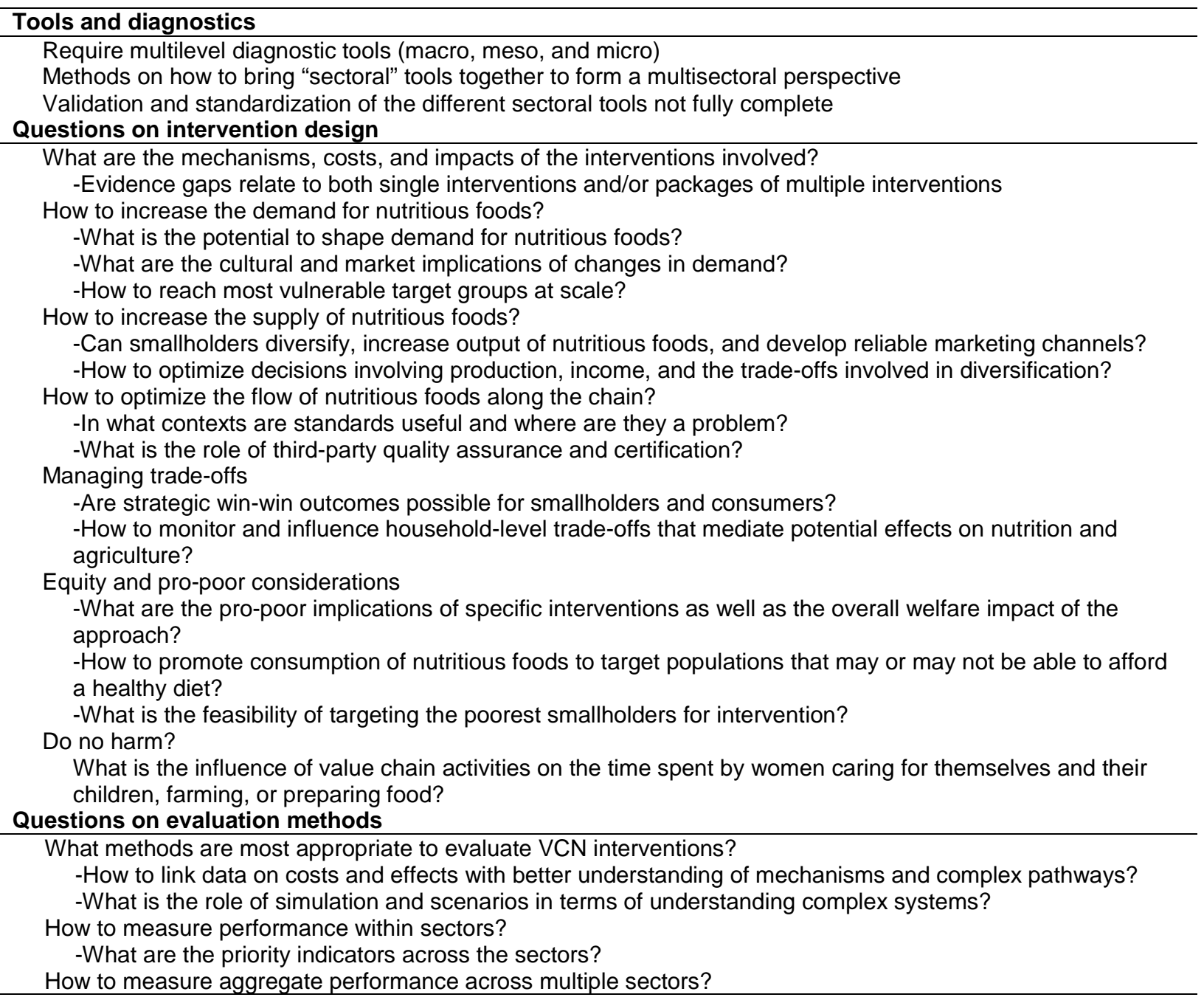

Source: Authors.

Note: $\quad \mathrm{VCN}=$ value chains for nutrition. 


\section{Tools and Diagnostics}

The complex and context-specific nature of VCN highlights the need for a set of comprehensive and flexible assessment tools to support the design and evaluation of interventions. Although a range of tools already exist for the different steps of the diagnostics proposed in this paper, ranging from macro-level food-system trends to individual-level dietary data, future work could integrate these tools to support a multisectoral perspective. Additional validation and standardization of some of the different sectoral tools are also needed.

\section{Questions on Intervention Design}

Despite the broad pathways for potential impact, VCN interventions are very context specific. Moreover, the VCN approach may involve bundles of interventions across one or more value chains. As mentioned previously, considerable evidence gaps exist related to the implications of both single and multiple interventions. Clearly, designing, managing, and evaluating this kind of approach is not straightforward. It is therefore important to be specific and carefully consider the nuances involved.

\section{How to Increase the Demand for Nutritious Foods?}

The emphasis on the consumer side centers on understanding the nutrition problem, including the available nutrition information, knowledge, attitude, and practices. Diagnostics of the nutrition problem are critical to ensure that the role of value chains and the potential opportunities are captured appropriately. Understanding consumers and intrahousehold dynamics, including gender roles, however, is not straightforward. Data on diets, a starting point for planning and adopting a VCN approach, are expensive to collect. Furthermore, the gap of information on costs of these diets is a major barrier in terms of understanding both the economic constraints consumers face in terms of healthy diets and the potential market opportunities for the value chain products. Streamlining diagnostic tools is an important area of ongoing work involving partnerships between researchers and practitioners.

A better understanding is required of the potential to shape demand for safe and nutritious foods, and the cultural and market implications of changes in this demand. In contexts where interventions aim to increase the consumption of nutritious foods, important questions remain on how to reach the most vulnerable at scale, not only from a short-term public health perspective but also from a long-term sustainability standpoint. The priority for nutrition interventions are children within the first 1,000-day window from conception to age two as well as pregnant and lactating mothers. It is important that the details involved in reaching these targets populations are developed explicitly as part of the intervention's design and evaluation. A related area involves demand-side considerations around the issue of overconsumption of processed foods, or unhealthy diets more generally, leading to overweight and obesity. Understanding the cost-effectiveness and feasibility of scale-up of alternative strategies to promote improved health and nutrition behaviors is another important area for research.

\section{How to Increase the Supply of Nutritious Foods?}

From the agricultural production side, the focus is on involving smallholder farmers, supporting diversification, and increasing output of nutritious foods while developing reliable marketing channels for these products. However, there is considerable heterogeneity and multiple factors to consider; with many smallholders being net buyers throughout the year, price effects could have a range of impacts on these producers. There also remain important questions for researchers regarding how to optimize decisions involving food production, income, and the trade-offs and risks involved in specialization versus diversification. It will also be critical to evaluate the most efficient methods for integrating multiple food products into the production and processing schemes of smallholder producers. 


\section{How to Optimize the Flow of Nutritious Foods along the Chain?}

Where the supply and demand for nutritious products already exists, the key focus is on interventions that enhance the nutrition added-value along the chain, including, at a minimum, nutrition content, food safety risks, prices, and quantities. Interventions in the middle of the chain (such as processing) are also key in terms of linking producers to consumers for a range of nutritious foods. However, the stakeholders involved are also very heterogeneous, including both private and public sectors, and understanding the coordination along the chain also requires careful assessment. In particular, because nutrition attributes are mostly unobservable, quality assurance and quality signaling are important. Although standards and common metrics, such as those involved in nutrient profiling of foods, can provide some relevant information for stakeholders at key points in the chain, the relationship between chain performance and regulatory environments is also complex, supporting the need for more evidence, such as on third-party quality assurance. Questions remain on how to provide credible and affordable means of certification, particularly in low-income settings. Similarly, assessing the challenges and opportunities for nutrition value-addition by processing foods, as in the production of nutrient-rich complementary foods for young children, alongside the pitfalls surrounding processed food more broadly is another important research area. In addition, the food production environment is changing due to pressures from climate change and population growth, highlighting the need to incorporate sustainability and resilience within the VCN framework.

\section{Managing Trade-offs}

In VCN, the heterogeneity across target groups, interventions, and potential effects is very broad. The impact pathways on consumers, producers, and other chain actors involve complex direct and indirect effects. At a strategic level, win-win outcomes for smallholders and consumers may be possible but not certain, and the trade-offs across the different outcomes made explicit in this paper require careful, context-specific analysis. For example, depending on the identity of consumers, putting consumers first might not be compatible or cost-efficient, at least in the short term, with sourcing from smallholders. However, by examining the costs and effects of interventions explicitly, it may be possible to justify any additional resources required for pro-smallholder engagement, or at least provide insights on longer-term solutions involving smallholders.

For smallholders, an important trade-off is reflected in the tension between increasing incomes and enhancing consumption of nutritious foods: the most profitable crops may be those with lower nutritional value (Henson et al. 2013). These trade-offs are complex and dynamic, and are also influenced by seasonal and secular trends. From this perspective, prioritizing objectives, monitoring intended and unintended effects, and "tweaking” intervention design in response to feedback from reliable monitoring and evaluation data will be important. Tailoring monitoring and evaluation methods to promote this flexible learning environment is also a key challenge for the research community. Understanding the effects of seasonality across demand and supply pathways, including health, dietary, and production variations, will be important (Devereux et al. 2008). It will also be important to understand the trade-offs involving household-level decisions and gender relations that mediate the effects on the nutrition, health, and agriculture pathways.

\section{Equity and Pro-Poor Considerations}

Critical issues across the potential VCN pathways are the pro-poor implications of specific interventions as well as the overall welfare impact of the approach as a whole. On the demand side, the central issue is how to promote consumption of nutritious foods to target populations that may or may not be able to afford a healthy diet. Similarly, on the supply side, key questions surround the feasibility of targeting the poorest smallholders and informal enterprises for intervention along the value chain; these are also more likely to involve women. 
Recent experiences in Latin America, such as Brazil’s social development programs, involve programs where explicit commitments were made to reach the poorest across both supply- and demandside pathways. In Brazil's case, explicit public financial and technical commitments were made to involve the poor in the supply of nutritious foods and then channel nutritious foods back into vulnerable households through social transfer programs (IPG-IG 2013). In Chile, public-private partnerships were developed to deliver social programs cost-efficiently (Epstein et al. 2004). Examining the roles and interactions between public and private sector stakeholders is essential. Rigorous analyses of the more cross-country experiences of the World Food Programme's Purchase for Progress (P4P) pilot will also provide important evidence on these issues.

\section{Do No Harm?}

The influence of value chain activities on the opportunity cost in time spent by women caring for themselves and their children, farming, or preparing food is another important area of ongoing and future research. On one hand, value chain activities involving processing may involve new products that are easier to prepare and have enhanced nutritional content. On the other hand, women's labor involvement in the value chain activities, including food production and processing, may reduce the time available for caring for younger children. Considering these gender-related trade-offs will be an important priority for impact evaluations in this field.

\section{Questions on Evaluation Methods}

Evaluating the VCN approach and related interventions involves generating policy-relevant evidence on costs and effects on producers, consumers, and stakeholders involved in pro-nutrition value-creation along the value chain activities. Optimizing value chain performance across the different sectors inevitably involves qualifying and quantifying trade-offs, and therefore complementing cost-effectiveness data with a better understanding of the mechanisms and impact pathways will be important. Appropriate evaluation methods are required to suit this breadth and complexity (LCIRAH/N-CRSP 2012). An analysis of the appropriate methods is beyond the scope of this paper. However, the conceptualization of the program impact pathways, the foundation for theory-based evaluations (Rossi et al. 2005, Habicht et al. 1999), presented in Section 2. "Lessons Learned So Far," provides an important first step in the evidence-generation process.

In terms of metrics, capturing overall performance of VCN interventions requires the collection of indicators from all the relevant stakeholders involved in the value chain activities. Developing detailed process maps that capture the activities and flows across the relevant chains can be a useful first step in identifying performance indicators (see the appendixes for some examples of process maps). The process maps can also be overlaid alongside the impact pathways developed in this paper to provide insights on possible effects on the different stakeholders involved. The breadth of indicators that are required to examine the whole system is clearly considerable, and in practical terms this poses another challenge to evaluators. In this context, prioritizing different indicators across the relevant disciplines, particularly in choosing primary evaluation outcomes, is extremely useful. 


\section{Examining Timing and Sequencing of Potential Effects}

Understanding the lags and sequencing in the potential effects along the pathways is another important element to consider explicitly in terms of intervention design and evaluation. For example, short-term studies may choose to focus on capturing changes across the processes and more proximal outcomes along the agriculture-nutrition pathways, including, for example, farming practices, production, sales, women's employment and role in household decisions, and nutrition knowledge and feeding practices, through to consumption and diets. More distal outcomes, including food security, income, and nutrition and health status, can also be measured but would likely be the primary focus of longer-term studies where there is also an increased likelihood of potential effects. In this context, process maps like those presented in this paper (Appendix A) also provide the basis for standardized frameworks to catalog inputs, outputs, and process indicators along the chain, the starting point for meaningful comparisons of cost-effectiveness. 


\section{APPENDIXA: EXAMPLES OF THE DESIGN OF VALUE CHAIN FOR NUTRITION PROJECTS}

This appendix includes case studies on the program theory for selected projects that were used to inform the materials presented in this paper. The design of each project was examined in detail, including assumptions about the nature of the problem the project was to address and the feasibility of the approach proposed to resolve it. Project literature was examined, capturing intervention needs, objectives, mapping processes, and possible impact pathways across value chains (World Bank 2007). Links between value chain activities and impact pathways were reviewed, identifying indicators for measuring impact on different target groups. Relevant crosscutting issues that affect overall performance of the system, including food safety and gender, were also captured based on existing literature.

\section{ACCESO}

ACCESO is a four-year USAID, Feed the Future, funded project implemented by Fintrac in Honduras that focuses on strengthening market-based systems for high-value crops, including horticulture crops, roots and tubers, fruit, and coffee. ${ }^{6}$ ACCESO works to increase productivity and adding value to traditional crops (corn and beans), and emphasizes the importance of improving nutrition while generating incomes.

\section{Needs and Target Groups}

The needs for the ACCESO project are multidimensional, generally poverty focused, and include:

- Nutrition and health: Maternal and child health, family planning, sanitation, and nutrition. Higher than national average rates of stunted and underweight children, a higher incidence of diarrhea in children under five, a higher percentage of houses with no sanitary facilities, and lack of private pharmacies and health clinics.

- Agriculture: Low market access for smallholders, poor production practices, low access to credit. Natural resources management and conservation are a challenge. Access to credit constrained by perceptions that agriculture is too risky, combined with small farmers' low capacity.

The project is active in six departments in the western regions of Honduras targeted on the basis of average levels of poverty and potential to transition to small-scale commercial agriculture (determined by access to land, adequate soils, water, and moderate topography, as well as the operation of micro, small, and medium enterprises [MSMEs]). Project households are selected on the basis of poverty criteria. Secondary beneficiaries include business owners and employees operating in value chains. Although their households may be above the poverty line, their participation is critical to the creation of jobs and income opportunities.

\section{Goals and Objectives}

The goal of the project is to improve the economic conditions and nutrition of rural families currently living in extreme poverty through financial development and increased incomes. ACCESO has six main components to achieve this goal:

\footnotetext{
${ }^{6}$ Sources include USAID-ACCESO Monthly Update, April 2011, and USAID-ACCESO Spotlight Analysis: Nutrition and Agriculture.
} 
1. Technical assistance and training to enhance the capacity of Honduras's poorest households in production, postharvest, management, and marketing skills.

2. Improving access to markets for farmers and develop links with producers and other MSMEs to determine which crops to produce, when to produce them, and production volumes according to market opportunities.

3. Expanding financial services in rural areas through existing financial intermediaries, rural loan associations, commercial banks, and service and input providers. Assistance in eliminating policy barriers that impede rural households' access to market opportunities.

4. Preventing malnutrition through training to improve the use and consumption of food.

5. Sensible management of the environment and natural resources.

6. Assistance to eliminate administrative barriers that hinder access to business opportunities for rural homes.

\section{Summary of Activities across Food Value Chain}

ACCESO incorporates a range of activities across a number of food and cash crop value chains, from production and postharvest support and strengthening market linkages to explicit nutrition- and healthfocused activities. ACCESO includes specific activities aimed at mainstreaming gender across the project. In addition to activities across value chains, ACCESO includes some work on identifying policy-level constraints that limit smallholder growth.

\section{Food Production}

Project activities include training on production-enhancing technologies to increase grain yields and reduce postharvest losses, such as preparing land, increasing plant densities, modifying fertilizer applications, utilizing weed control systems, using drip irrigation, protecting water sources from contamination, using integrated crop and pest management (IPM), using pesticides, and standardizing harvest and small-scale storage systems. The project also provides support to small-scale, on-farm supplemental income sources, such as surplus from kitchen gardens (see below), small orchards, and poultry production, and off-farm employment. Selected local market high-value vegetable growers are also assisted to produce under contracts with supermarket chains, processors, and export companies. Improved production practices for coffee farmers focus on lengthening harvest periods, increasing yields, maintaining and determining quality, and obtaining certifications to help expand into higher-value coffee lines, including specialty, organic, Fair Trade, and others. Coffee producers are also provided opportunities to diversify into high-value horticultural value chains. Training is provided for women in the cultivation of home gardens to provide a source of healthy seasonal fruits and vegetables. Teams including agronomists and nutritionists work to support families to select crops that are high in nutrients and are relatively easy to grow, including leafy green vegetables, sweet potatoes, tree fruits, passion fruit, taro, plantains, and bananas. ACCESO also provides support for small-scale aquaculture and livestock production to further increase household dietary diversity.

\section{Postharvest Supply Chain}

The project supports existing smallholder farmer groups by providing them with training and tools to ensure or improve basic business practices, locate new buyers and markets, obtain required group-level certifications, develop logistical supply programs with buyers, and expand the range of services available to members. 


\section{Consumers}

ACCESO's nutrition strategy is designed to improve access to a more diversified daily diet through increased nutritional awareness and productive gains made by home gardening or commercial farming. The project's nutrition activities focus on home gardens; information, education, and communication; and small-scale infrastructure and other activities that affect health and nutrition. Nutritionists provide regular trainings in nutrition, childcare, illnesses prevention, hygiene and sanitation practices, and family planning. To expand and improve the health and nutrition messages to the wider population, nutritionists work to build capacity of health volunteers by providing training and tools, involving them in health activities in the community, and including them as beneficiaries of the project's economic development activities. ACCESO also provides health infrastructure investments, including the installation of latrines to improve sanitation and reduce contamination of water sources; the introduction of fuel-efficient woodburning stoves to decrease the level of indoor pollution; and improvements in community water infrastructure, water source protection, and in-house water chlorination.

\section{Impact Theory}

ACCESO is designed as an integrated set of activities across the food system geared at increasing the supply and demand of nutritious foods. A set of complementary investments in health infrastructure is also provided to support the overall impact on health and nutrition. On the supply side, extension, training, and financial services are provided to marginalized smallholders. Supply-side support is coupled with strengthened links to markets and involve no direct procurement. Nutrition education to rural consumers is also used as a market pull mechanism, shaping the demand for nutritious foods and healthy eating practices. This knowledge, coupled with the increased incomes from the agricultural assistance and health infrastructure investments, supports the overall improvements in health and nutrition.

\section{Sustainability and Scale}

ACCESO's approach involves tackling smallholder supply-side constraints while developing market linkages. The sustainability of the approach involves building the capacity of market actors to continue providing services beyond the duration of the project. Another important entry point for sustainability involves engaging with policy-level stakeholders to identify constraints in terms of smallholder market participation. ACCESO aims to reach at least 31,800 households, composed of 30,000 households living in poverty, including a minimum of 18,000 households living in extreme poverty, 1,000 commercial-scale producers of horticultural crops, and 800 off-farm rural MSMEs.

\section{Agriculture and Nutrition Extension Project (ANEP)}

ANEP seeks to sustainably raise agricultural productivity and promote effective market linkages to improve the nutrition of poor rural and urban households in the south of Bangladesh and the Nepal plains. ${ }^{7}$ ANEP began in 2012 as a partnership among International Development Enterprises, World Fish, International Maize and Wheat Improvement Centre (CIMMYT), International Rice Research Institute, Save the Children, and others, and is funded by the European Union.

\section{Needs and Target Groups}

The needs for the ANEP project are multidimensional, generally poverty focused, and include:

- Nutrition and health: Undernutrition, micronutrient deficiencies, unhealthy diets, and nutrition practices. Nationally, 41 percent of children under five years are moderately to severely underweight and 43 percent suffer from moderate to severe stunting (NIPORT 2013).

\footnotetext{
${ }^{7}$ Sources include description of project action provided by IDE.
} 
- Agriculture: Low market access for smallholder farmers and low access to improved production technologies. Smallholders lack access to improved technologies due to weak linkages between research and extension and between research systems, the private sector, and development projects.

- IDE selected geographic areas with relatively high poverty rates, and where one or more partners were currently operating. The locations in Bangladesh represented excluded households from mainstream development and ethnic/caste minorities in urban areas. ANEP targets poor and socially excluded rural and urban households that have the potential to improve the production and marketing of nutritious foods and improve nutrition through the intervention. Target households included households with pregnant women, lactating mothers, and children under five years of age.

\section{Goals and Objectives}

The overall goal of ANEP is to improve the food security and nutrition of poor and vulnerable households, with the following specific objectives:

- Improving livelihoods through increasing farm productivity.

- Improving nutrition through better access to nutritious foods.

- Making the benefits last through sustainable market linkages.

\section{Summary of Activities across Food Value Chain}

ANEP includes a range of activities involving stakeholders at district and community levels across the food value chain (see Figure A.1for a stylized example, with key steps [labeled I-V] described below).

\section{Food Production}

ANEP undertakes a range of production support activities (1) for smallholder groups, including:

- Vegetables: Facilitates access to off-season, nutrient-rich varieties through deepening the engagement between seed retailers and producer groups, and building the capacity of farmers to invest in activities that are more profitable (see below). This creates demand for quality inputs, such as seed and fertilizer, as well as key services and production support technologies, such as irrigation and IPM technologies.

- Fisheries: Introduces carp-poly culture with multiple carp species with different feeding niches and nutrient-rich small fish and supports integrated vegetable production on pond dykes.

- Maize, wheat, rice, and legumes: Minimum tillage to improve soil quality, water use, and yields, while reducing labor; irrigation strategies, including bed planting and alternating wetting and drying for rice; decision tools for soil fertility management; dissemination of higher-yielding, stress-tolerant, and more nutritious crop varieties, including legumes and high-protein maize; promotion of low-cost seed storage technologies; and market and enterprise approaches for mechanization and technology adoption.

In addition to facilitating access to inputs and other production-enhancing technologies, ANEP supports the development of production and sales plans based on demand-side market information supplied by market chain actors (typically output market actors such as aggregators and small traders). The plans also provide the basis for feedback on constraints for particular production strategies that are reprogrammed into ANEP support (2). 
Figure A.1 Stylized food value chain for ANEP project with potential impacts across different target groups

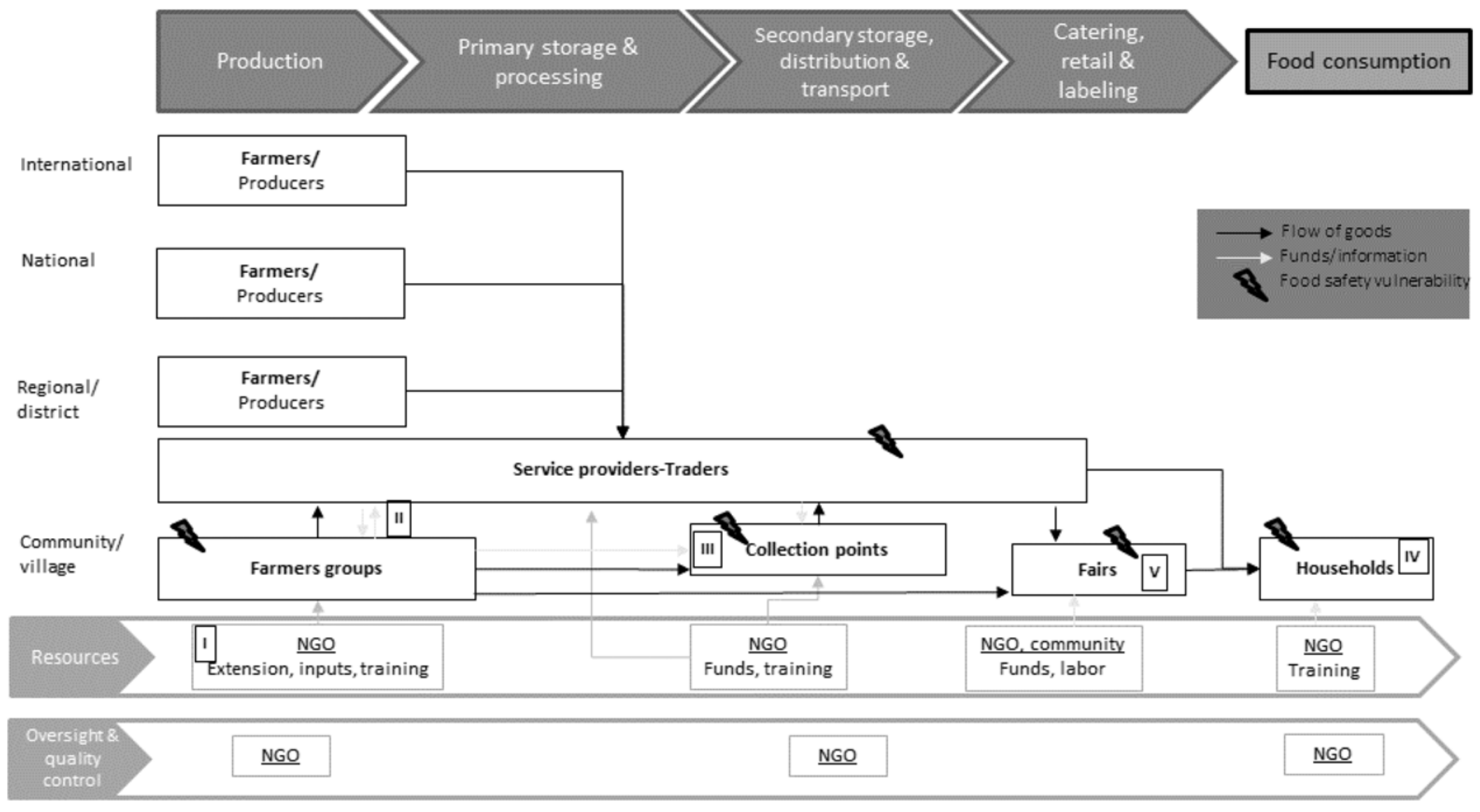

Source: Authors. 


\section{Postharvest Supply Chain}

ANEP activities work to support the development of sustainable market linkages for both rural producers and urban consumers through the strengthening of community-level aggregation institutions, or collection points. Collection points also act as supply-side hubs through which production and sales plans can be coordinated and linkages between actors strengthened, particularly with lead firms (3). Management committees coordinate collection point functions, liaising with lead firms and larger buyers.

\section{Consumers}

ANEP undertakes household nutrition education that promotes the consumption of nutritious foods and healthy nutrition practices, including infant feeding practices and basic hygiene (4). Women in each urban or rural group receive 12 sessions over three months using a participatory action learning approach where the group learns a nutrition practice and then applies it in action through activities such as cooking demonstrations. In addition, ANEP organizes pushti-mela, or nutrition festivals/farmers' markets (5), to attract urban consumers to whom the farmers and mobile traders can sell fresh produce. The entertainment provided at the festival, including songs about healthy foods, cooking demonstrations, and cartoon showings for children, reinforces the nutrition education component of the intervention.

\section{Impact Theory}

ANEP is designed as an integrated set of activities across the food system geared at increasing the supply and demand of nutritious foods. On the production side, extension, credit, input, and other productionenhancing activities are provided to marginalized smallholders. In rural areas, the project also plays the role of market facilitator or business broker for the farmers' groups. Supply-side support for smallholders is coupled with market development through access to community-level service providers and aggregation points. Links are strengthened to an open market and no direct procurement is involved. Nutrition education to urban and rural consumers is used as a market pull mechanism, shaping the demand for nutritious foods and healthy eating practices. Food fairs are used to reinforce the nutrition messaging and strengthen the market links between producers and consumers. The increase in supply of nutritious foods complements the ANEP nutrition education component that improves knowledge of basic nutrition practices, infant feeding practices, and hygiene among urban households.

\section{Sustainability and Scale}

ANEP adapted the participatory market chain approach to build the capacity of market actors to continue providing services beyond the duration of the project. The ANEP sustainability strategy is aimed at enabling the service providers to take over the NGO activities (such as training, support, and funding). In rural areas, for example, Farm Business Advisors can be created to provide business brokering services (can be led farmers or input/output market actors) that provide this service on a commission basis. In addition, the strengthening of market management committees to continue and improve coordination can lead to new initiatives and strategies without project support. The requirement for market actors to collaborate in these risk-and-reward strategies provides the glue that will bond the groups and ensure they can adapt to changing circumstances and lead and benefit the communities beyond the duration of the ANEP.

In Bangladesh, ANEP aims to reach approximately 10,000 households directly and 30,000 households indirectly through the value chain. 


\section{CIPIAVDRC Horticulture Project in Bangladesh}

This USAID-funded project in Bangladesh aims to increase the consumption of healthy foods, especially vegetables and orange-fleshed sweet potato, and involves collaboration among AVRDC, CIP, and WorldFish. Project activities work to increase food supply, strengthen value chains for relevant crops, and promote healthy eating practices. A sub-project linked to the CGIAR Program on Agriculture for Nutrition and Health (A4NH), working under the umbrella of the USAID-Horticulture Project, is also looking to leverage the networks of seed suppliers to reach a large number of farmers and households. This section is based on the program theory as captured in Hanson et al. (2012) and Yang (2013).

\section{Needs and Target Groups}

The needs for the project include:

- Nutrition and health: Micronutrient deficiencies, unhealthy diets, and nutrition practices. Despite significant improvements in income growth over the past decade, more than 43 percent of preschool-age children are stunted and 56 percent are underweight. Micronutrient deficiencies, including vitamin A, iron, and zinc, are also highly prevalent.

- Agriculture: Insufficient vegetable supply, low productivity, large seasonalities of production, and pesticide abuse. Bangladesh, with a high population relative to land area, out of necessity applies intensive cultivation practices. With this high population density, current cropping intensity and the use of hazardous pesticides are very high.

The project operates in four districts (Jessore, Faridpur, Barisal, and Patuakhali) in the southern region of Bangladesh. The project directly targets marginal and smallholder farmer households involved in the production of potato, sweet potato, and vegetables. A range of other stakeholders are targeted indirectly through value chain activities.

\section{Goals and Objectives}

The overarching goal of the USAID-Horticulture Project in Bangladesh is to "improve nutrition, food security, and livelihoods through increased micronutrient intake, and increased incomes from improved crop productivity and strengthened market linkages” (Hanson et al, 2012).

The goal of the A4NH sub-project is to increase the consumption of nutritious food in Bangladesh, especially vegetables and orange-fleshed sweet potato (OFSP), through activities designed to boost production and increase consumer demand.

The aim of the sub-project is to increase the supply of nutritious foods and increase the consumption of healthy diets. Medium-term objectives include enhanced public awareness and demand for and access to nutrient-rich vegetables for rural and urban poor, with emphasis on nutritious diets for women and children.

\section{Summary of Activities across Food Value Chain}

The USAID-Horticulture Project involves a range of activities to enhance smallholder production that are coupled with postharvest chain strengthening and demand creation activities. The project adopts the participatory market chain approach (PMCA) to identify constraints (such as inefficient production practices, multiple intermediaries, and high postharvest losses) and opportunities across relevant value chains. Interventions are then introduced to tackle these constraints.

The A4NH sub-project looks to test a specific intervention to enhance nutritional outcomes. Existing agriculture extension and marketing services of private-sector seed suppliers are leveraged to also provide nutrition messaging to producers and consumers. See Figure A.2 for a stylized view of the project, with key steps (labeled 1-5) described in more detail below. 
Figure5 Stylized food value chain for the AVDRC project with potential impacts across different target groups

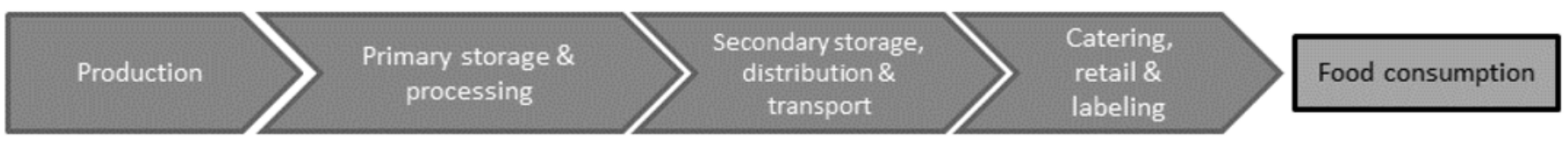

International
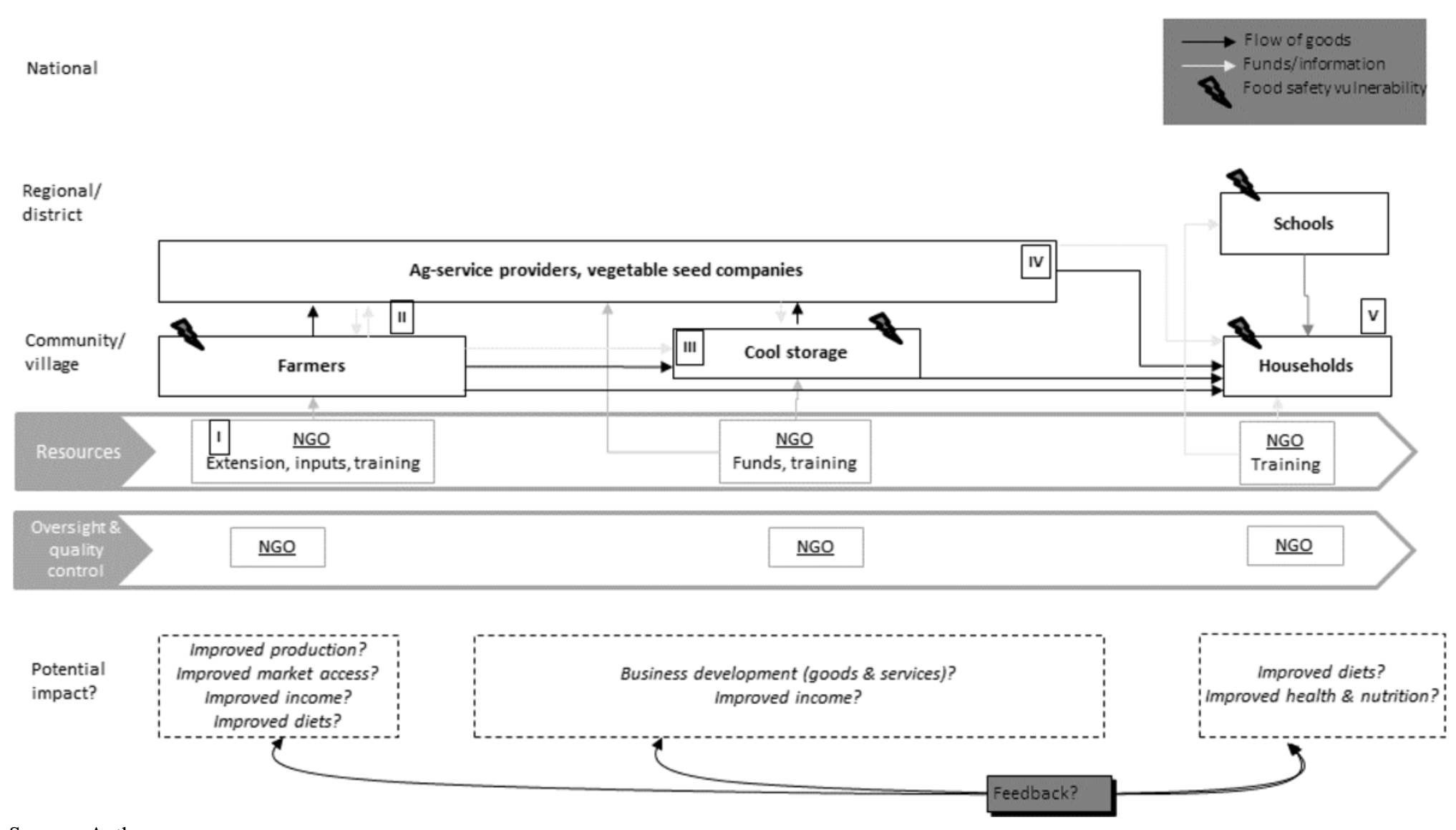

Source: Authors.

Note: $\quad$ NGO = nongovernmental organization. 


\section{Food Production}

The umbrella project activities include training and extension services on seed production, crop management practices, and cropping systems (2). The project provides a range of interventions, including leveraging the Bangladesh vegetable breeding network, participatory selection of elite varieties, summer tomato training and component improvement, design and promotion of IPM strategies, and home gardens for both training and promotion. The interventions include gender components, with special regard to women's role in home gardens and income-generating technologies, such as grafting, where they have the bulk of the responsibility, and income potential from the marketing of relevant crops. In the A4NH subproject, the existing activities of seed suppliers are enhanced by including an additional component on nutrition, providing the project with a network to influence large numbers of farmers (2).

\section{Postharvest Supply Chain}

The project activities also involve strengthening smallholder market linkages and storage and aggregation

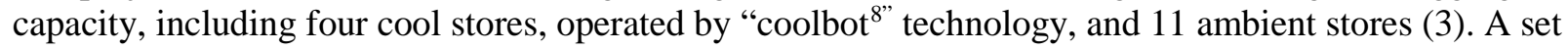
of training and training of trainers programs for smallholders, covering postharvest management practices and the use of cool storage for potatoes, sweet potatoes, and other horticultural products, are also included in the project.

\section{Consumers}

The project promotes healthy nutrition practices through multiple channels, including OFSP consumption promotion within the community, and sensitizing farmers on the nutritional benefits of relevant crops (5). The project also includes pilot school garden planting and promotion of consumption of OFSP and vegetables in schools, with the objectives of promoting nutritional awareness on the consumption of vegetables and OFSP and fostering child-to-parent behavior change. Through these activities, the project reached 7,065 students who later motivated their parents and established home gardens and OFSP vine propagation in their households. The project also developed training materials and selected 200 Community Nutrition Scholars who will use these training materials for raising awareness at the village level. The A4NH sub-project supports seed suppliers to fine-tune nutrition promotion messages, train agricultural staff in nutrition and nutrition awareness, and measure the effects of nutrition promotion on consumer behavior (4).

\section{Impact Theory}

The USAID-Horticulture Project is designed to increase both the supply of and demand for nutritious foods. On the production side, extension, inputs, and other production-enhancing activities are provided to marginalized smallholders. Supply-side support for smallholders is coupled with postharvest chain strengthening, including improved storage and aggregation. Links are strengthened to an open market and no funds for direct food procurement are involved. Nutrition education to producers and consumers is used as a market pull mechanism, shaping the demand for nutritious foods and healthy eating practices.

\section{Sustainability and Scale}

The project adopted the PMCA to build the capacity of market actors to continue providing services beyond the duration of the project. Leveraging seed companies' activities that have strong farmer extension components and also promoting the consumption of vegetables, can provide a platform to sustainably reach thousands of farmers throughout the country with a marginal investment. Promoting increased production and consumption of vegetables is in the interest of vegetable seed companies. Seed companies would gain financially by increased production and consumption of vegetables. The project has directly reached approximately 22,000 farmer households over the past 2 years.

\footnotetext{
${ }^{8}$ See www.storeitcold.com/howitworks.html.
} 


\section{East Africa Dairy Development Project (EADD 2) in Kenya, Tanzania, and Uganda}

EADD is a poverty reduction project funded by the Bill and Melinda Gates Foundation that began in 2008 in Kenya, Rwanda, and Uganda. EADD is led by Heifer International in partnership with the International Livestock Research Institute, TechnoServe, the World Agroforestry Center, and African Breeders Service. This section focuses on the second phase of EADD's activities in Kenya, Tanzania, and Uganda (2014-2018) and is based on multiple sources.

\section{Needs and Target Groups}

The project is designed to alleviate two main constraints dairy smallholders face:

- Low availability of affordable and high-quality inputs and services.

- Cash constraints to access these inputs and services.

In East Africa, a large proportion of household income comes from dairy. Even so, many smallholders lack business skills, knowledge of proper production technologies, and access to inputs and services that are needed to increase dairy production and income. Furthermore, challenges to growing a robust dairy value chain in East Africa are numerous. There is an inconsistent supply of milk of variable quality, which is related to farmers' limited access to inputs and services. Processors have limited capacity due to a poor understanding of consumer demand for milk and dairy products, limited product development, and poor-quality plant operations. Furthermore, there are issues with seasonality and associated price fluctuations, fragmented markets, lack of trust among actors in the value chain, and underinvestment at all levels.

EADD site selection is undertaken using a demand-based approach, driven by both communities and markets. In EADD 1, sites were selected based mainly on farmer population, cattle density, and existing producer groups. EADD 2 will consider farmer accessibility and usage, potential for privatesector investment, and probability of commercial success. Assessments involve rapid qualitative analyses combined with geographic information system data describing access to markets and infrastructure. The target farmers in EADD 2 include:

- Active suppliers (primary targets): Farmers supplying at least 90 times/year and/or accessing inputs and services two times/quarter. Represents 50 percent of direct beneficiaries targeted.

- Direct beneficiaries (semi-active farmers): Farmers supplying milk to the hubs, but less than 90 times a year and/or access inputs and services less than once per quarter.

- Secondary beneficiaries: Value chain actors benefiting from economic activities at the hub, including providers of financial services, feed, animal health services, on-farm laborers, extension staff, milk transporters, community animal health workers, and unregistered farmers attending training.

- Indirect beneficiaries: Residents of catchment area benefiting from increased economic activity, through adopting practices of neighbors, higher prices for milk, and overall economic growth.

\section{Goals and Objectives}

The objective of the EADD 1 was to double the dairy incomes of 179,000 smallholder farming households in ten years. The goal of EADD 2 is to achieve sustainable livelihoods for 136,000 smallholder farming households, as well as stimulate income growth for an additional 400,000 secondary beneficiaries, by 2018 through a competitive and inclusive dairy industry. The objectives of EADD 2 include promoting: 
- sustainable dairy production and productivity;

- increased access to competitive and expanded markets for dairy value chain actors;

- women's empowerment;

- hub replication.

\section{Summary of Activities across Food Value Chain}

The cornerstone of EADD is the hub, a community-based milk bulking and collection center, with or without facilities that keep the milk chilled for transportation, where farmers can access inputs and services on credit, based on their milk deliveries. Farmers can access inputs and services even when they do not have any cash through a "check-off system," which deducts the cost of the services from their monthly dairy earnings at the hub. In some hubs, savings, lending, and other services may be provided through linked financial service associations, microfinance institutions, and Savings and Credit Cooperative Organizations (SACCOs). Hubs are coordinated by a producer group formed for that express purpose. Farmers register with the producer groups when selling milk or buying inputs and services. Based on the learning from EADD 1, there are three types of hubs in EADD 2: pre-bulking, bulking, and chilling plant. These are described more in Table A.1.

Table A.1 Key activities by type of hub

\begin{tabular}{|c|c|c|}
\hline Hub type & - & Activity \\
\hline $\begin{array}{l}\text { Pre-bulking } \\
\text { hub }\end{array}$ & - & $\begin{array}{l}\text { Does not offer bulking or chilling } \\
\text { Most viable when milk volume is too low to warrant collective action, and/or milk traders are } \\
\text { well organized and offer "fair" prices to producers } \\
\text { Typically found in extensive production zones or near large urban markets } \\
\text { Builds on the existing relationship between producers and traders, organizes and formalizes } \\
\text { this relationship through producer group registration, and introduces and facilitate service } \\
\text { providers to provide dairy-related inputs through the check-off system (credit) } \\
\text { Formalizes marketing channels by working with traders who are registered with an } \\
\text { association and often have a competitive advantage over producer groups due to higher } \\
\text { prices they offer }\end{array}$ \\
\hline Bulking hub & & $\begin{array}{l}\text { Offers milk collection, but no chilling, and may include or be expanded to include small-scale } \\
\text { processing for preservation, like batch pasteurization or yogurt production } \\
\text { Operates with up to } 250 \text { farmers } \\
\text { Often linked to informal markets; targets rural farmers, but is equally well suited for } \\
\text { urban/peri-urban (intensive) and extensive (or semi-intensive) sites } \\
\text { Success is typically driven by the raw milk market chain }\end{array}$ \\
\hline $\begin{array}{l}\text { Chilling plant } \\
\text { hub }\end{array}$ & - & $\begin{array}{l}\text { Offers chilling } \\
\text { Operates with a minimum of } 500 \text { farmers, bulking an average of } 2,000 \text { liters/day } \\
\text { Most viable when milk production is fairly intensive, there is unmet processor demand, and } \\
\text { access to demand and/or larger markets is constrained by distance } \\
\text { Significant start-up costs (US } \$ 90,000) \text { and are either farmer owned or process owned, rented } \\
\text { by farmers } \\
\text { Success is driven by the formal milk market, specifically processor demand }\end{array}$ \\
\hline
\end{tabular}

Source: Authors.

\section{Food Production}

Farmers, regardless of whether or not they deliver milk to the hub, access inputs and services primarily through the network of businesses affiliated with the hub, including the following core elements: 
- Feeding, which includes strategies to address seasonality, such as postharvest storage to make higher-quality feed available during the dry season, planted forages, silage, hay production, and improved conservation of crop residues.

- Improved animal breeding aimed at increasing production and smoothing out seasonality, relying on two approaches: artificial insemination (AI) offered through the hubs and a bull scheme. Accessibility of AI services will be increased through a training of trainers approach.

- Investments or interventions to address water availability, access, security, and utilization.

- Improved animal health by identifying, monitoring, and treating cattle diseases; delivering appropriate training; connecting to existing early warning systems; and ensuring access to trained veterinarians.

- Milk quality improvements on the production side (with two more on the postproduction side) through better training in proper milk handling, hygiene, and sanitation, with plans to pilot new strategies such as mechanized milking.

Training will be supported through extension services, which might be a liaison officer that coordinates extension services on behalf of a producer group or a full-time, qualified staff member delivering extension through the hub.

\section{Post-Production Supply Chain}

Farmers and traders deliver milk directly to the hubs. Each hub is different depending on the hub type, milk buyer type, availability of milk buyers, and a number of other factors that affect the prices farmers receive and the arrangements hubs have with buyers. In the most general terms, by aggregating milk collection, the farmers are able to negotiate for better prices in both informal and formal markets. If the hub has cold storage facilities, this encourages processors to recognize the producer groups as important partners. EADD is targeting processors, such as Sameer, New Kenya Cooperative Creameries, Brookside, and Pearl Dairies. For EADD 2, a total of 50 hubs will be supported by EADD, with eight in Kenya, 33 in Uganda, and nine in Tanzania. Quality assurance mechanisms in place at the hubs also improve the quality of milk sold in informal markets. EADD 2 has two strategies around milk quality improvement on the supply side, including the promotion of differentiation of milk with lactometer tests (separating lowcount milk from high bacteria milk into different cooling tanks) and the piloting of a quality-based pricing system in Kenya.

EADD 2 will also strengthen capacity of staff and producer groups to recognize gender constraints to project participation and identify opportunities to address inequity in project design. Activities aimed at increasing women's access to dairy-related production assets will include, for example, keeping producer groups open at night to allow women to sell milk from the second milking, encouraging hubs to allow more than one household member to be registered, helping women and youth get identity cards (a requirement for registering), providing trainings at times and locations convenient for women, supporting mobile money mechanisms, and improving women's access to credit. Another part of the strategy is to increase the percentage of women participating in producer groups and in leadership.

\section{Consumers}

Demand for milk varies across the three countries; however, EADD has no specific plans to stimulate demand for dairy or monitor changes in household milk consumption beyond consumer market surveys. Nevertheless, the proposal describes intents to explore strategies to increase milk consumption (for example, private sector funded and processor-led school milk program). 


\section{Impact Theory}

EADD realized in the first phase that milk volumes are what drive farmers' decisions about where to sell their milk. Therefore, the emphasis in EADD 2 is on the production side in order to make the value proposition of the hubs more attractive. The underlying assumption of the hub approach is that market access can motivate farmers to increase their dairy production, as well as productivity and quality, which will increase incomes and improve food security. The inputs and services provided at the hubs on the check-off system help farmers increase dairy production. The aggregation of milk collection in the hub then links farmers to the formal market. By using the collective action of the producer groups, the hubs are designed to be sustainable post-project in what EADD describes as social terms (producer group cohesion, governance, leadership, technical capacity) and economic terms (profitability, cash positivity). The benefits to consumers are expected to come mostly from a more efficient and self-regulated informal market for milk, in addition to increasingly affordable and high-quality processed milk and other dairy products offered through the formal market.

During EADD 1, the average monthly milk intake at the dairy enterprises increased from 529,000 liters to 3 million liters and farmers now earn an average of US\$0.3 per liter of milk delivered, 50 percent more than they earned in 2008.

\section{Sustainability and Scale}

The sustainability strategy of EADD relies upon the producer groups to continue providing services beyond the life of the project. EADD works with the hub's producer group to develop from the start an exit strategy with a clear timeline, milestones, communication plan, and budget. The intent is for privatesector partners to be involved in the creation of this exit strategy to improve the likelihood that they will remain involved when EADD ends. In addition, the project uses a sustainability assessment tool with program implementers and producer groups to identify sustainability gaps and guide program planning.

EADD's plans for reaching scale rely on NGOs, national governments, and the private sector to replicate or syndicate the hub model. They believe that such action can be achieved if the project can support enough farmers to meet government expectations and prove to private-sector partners across the value chain that the hub approach is a profitable, viable, and sustainable business model. In Uganda, the Dairy Development Authority is already encouraging development implementers to adopt the hub approach in services to farmers. In Tanzania, where the dairy industry is less developed, EADD 2 will strengthen the organization capacity of producer groups in order to link them to national institutions, such as the Tanzania Milk Producers Association and the Tanzania Milk Processors Association, and facilitate the completion of the Ministry of Livestock and Fisheries Development's National Master Dairy Strategy, which is intended to outline investment priorities and coordinate roles and responsibilities for industry stakeholders. In Kenya, the success of EADD combined with public and private partnerships and an enabling environment puts it in a promising position to quickly go to scale. The major local banks in Kenya each have a fund of more than $\$ 2$ million, which they are required by law to lend to dairy farmers for purchasing milk chilling equipment, transportation trucks, and dairy cows, and investing in financial services and other dairy ventures. EADD 2 will also be following up on how to test quality-based pricing mechanisms in improving milk quality for its nutrition programs.

\section{Laiterie du Berger Dairy Value Chain Project in Senegal}

The Laiterie du Berger (LDB) is a social venture operating in the Senegal River Valley. The LDB's business model involves producing high-end dairy products for mostly urban populations, based on fresh milk collected from herders living within $50 \mathrm{~km}$ from its processing plant. A range of partners, including Danone Communities and Crédit Agricole-Grameen Foundation, among others, provide support to the LDB activities. LDB in partnership with IFPRI is testing an innovative intervention to examine whether a health-related product targeting young children can be provided through the existing supply chain, and whether in return this can be leveraged to enhance the efficiency of production. This section is based on the program theory as captured in multiple sources (Hidrobo et al. 2013; Parisse 2012). 


\section{Needs and Target Groups}

The overall needs for the intervention include:

- Nutrition and health: Micronutrient deficiencies, unhealthy diets and nutrition practices.

- Agriculture: Poor market access for pastoralist milk producers.

Anemia is a public health concern in Senegal. The national prevalence of anemia is estimated at 83 percent for children under five, and at 54 percent of their mothers (NIPORT 2011). According to the impact evaluation baseline, anemia is also highly prevalent in the target population, with rates peaking at over 90 percent for children in the 12-24 months range. Maternal anemia prevalence rates were estimated at more than 40 percent (Hidrobo et al. 2013).

Demand for dairy products in Senegal is substantial, with the total demand reaching 400 million liters per year for a population of 12 million (DIREL 2004). Senegalese households on average dedicate 5 percent of food consumption and expenditures on dairy products. Despite this significant market, approximately two-thirds of this demand is met through imports. Factors driving these trends include a general lack of reliability on the supply side (which is heavily affected by seasonality), the movements of pastoralist herders, and the general perceptions among herders that dairy is a secondary product of cattle rearing, dedicated to home consumption and for women to generate petty cash (Hidrobo et al. 2013).

LDB targets cattle herders and their households living within a $50 \mathrm{~km}$ radius of the processing plant in Richard Toll in the Peul region. The micronutrient-fortified intervention being evaluated by IFRPI targets children between two and five years of age living in the producer households.

\section{Goals and Objectives}

The goal of LDB is to support the livelihoods of farmers, ensuring a regular source of income by collecting output on a daily basis. LDB seeks to create value by transforming the milk into a range of dairy products for both urban and rural consumers.

The micronutrient intervention is looking to test (1) whether the LDB supply chain can be leveraged to deliver fortified yogurts to infants within supplier households, (2) whether such products effectively help improve the nutritional status of these children, and (3) whether these health services encourage suppliers (and in particular women) to increase their milk delivery to LDB (Hidrobo et al. 2013).

\section{Summary of Activities across Food Value Chain}

The dairy is located in an area of relatively low population density, where herds move to follow fresh water and pasture, including an annual migration during the dry season (Parisse 2012). LDB activities focus mainly on aggregation and postharvest value-addition, creating a number of dairy products for urban and rural markets. See Figure A.3 for a stylized example with key steps (labeled I-VI) described below. 
Figure A.3 Stylized food value chain for LDB dairy project with potential impacts across different target groups

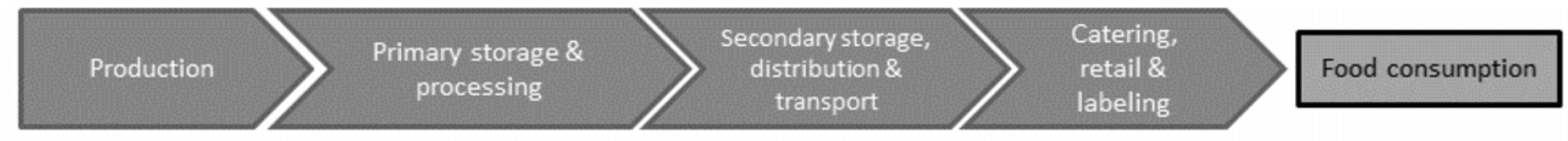

International

National
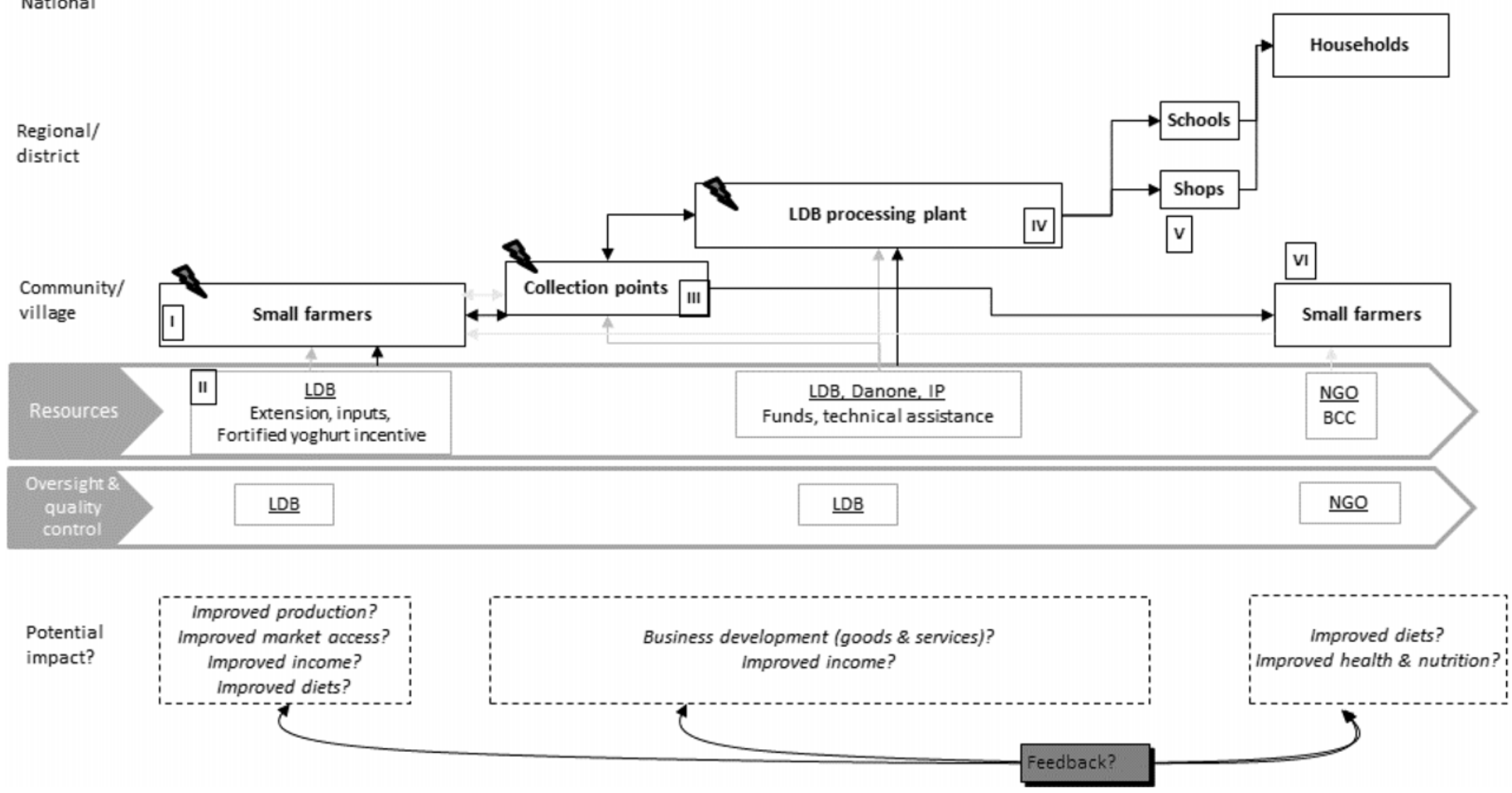

Source: Authors. 


\section{Food Production}

LDB has formed a reliable base of about 700 milk suppliers (1) from 94 collection points along four main collection routes. Agreements between LDB and the suppliers are trust based and non-contractual. Suppliers are provided with a numbered milk container, including an identifier that is used by the plant to monitor output and manage monthly payments. Milk containers can be shared among farmers belonging to the same family or compound. Milk production follows seasonal trends: milk output decreases substantially in the dry season due to scarcity of pasture. Milk output peaks during the rainy season, but milk collection can be challenging during these times because of flooding. To increase output in the dry season, LDB sells animal feed to milk suppliers at competitive prices, in quantities proportional to the volume of milk supplied. The cost of the feed is subtracted from the milk payments at the end of the month. In 2010, the Laiterie du Berger sold FCFA 13 million in feed to its suppliers. LDB also provides hygiene, feeding and veterinary advice (2).

\section{Post-Production Supply Chain}

Milk is collected twice daily from the collection points (3) and transported to the factory in Richard Toll. The factory originally produced a range of products, including fresh milk, yogurt, juices, and cream. In 2009, however, the production was focused on yogurts and cream only, including a number of premixed yogurts (Thiakry) with micronutrient fortification (4). LDB created a new brand (DOLIMA) that currently accounts for 13 percent of the dairy product market. The premix for the Thiakry fortification was developed by Danone Communities, a stockholder of LDB. The micronutrient-fortified yogurt includes $2.1 \mathrm{mg}$ of EDTA iron, $2.25 \mathrm{mg}$ of zinc, $24 \mu \mathrm{g}$ of Iodine, and $120 \mu \mathrm{g}$ of vitamin A and is packaged in a 80 g sachet called “Dolima Doolé” (“makes me stronger”). LDB supplies more than 6,000 point of sales, including modern shops, gas stations, and mobile traders in Dakar and Saint Louis. The majority of shops are small proximity shops, usually equipped with a single fridge or freezer where all categories of cold chain products are stored. In order to be able to deliver products in urban areas with poor roads, LDB developed both a delivery "pouss" service and some dedicated shops (5). LDB also distributes Dolima Doolé in 19 schools in Dakar. LDB receives technical assistance from Danone on research and development and quality control.

\section{Consumers}

The pilot intervention included a behavior change campaign (BCC) focusing on promoting infant and young child nutrition practices (VI). In addition, an incentive system was developed based on a preintervention commitment from the producer households to supply at least 0.5 liter of milk per cow per day for five days a week; in return, they receive one sachet of Dolima Doolé fortified yogurt per child aged two to five years per day. The yogurt is delivered daily by the same LDB truck that collects the milk.

\section{Impact Theory}

The LDB model is intended to provide a regular market for herders, who can sell their product on a daily basis without traveling to market. The increased and more regular market access in turn provides incentives to increase production, particularly during the dry season. According to LDB data, in 2010, 680,000 liters of fresh milk were collected, representing a 23 percent increase in comparison with 2009 (Hidrobo et al., 2013). Another element of the LDB model hinges on important gender dynamics. Generally, women are in charge of milking, and men collect the monthly payment (Hidrobo 2013). According to LDB's field experts, the disincentive that the system generates for women's effort at the time of milking is important, such that milk supply in the dry season could be increased by up to 50 percent were women rewarded directly. The pilot intervention providing fortified yogurt in return for a steady supply seeks to tackle this constraint, and at the same time provides a direct intervention addressing micronutrient deficiencies in children under five. 


\section{Sustainability and Scale}

The LDB is a social enterprise with a business model that has shown remarkable success to date. The transaction costs, in terms of milk collection directly from producers, are offset by the benefits from a reliable supply. However, this balance is not static. For example, during the dry season production volumes fall but LDB faces the same transportation costs. Smoothing the seasonality of production by increasing output in the dry season is an important factor in LDB's sustainability.

The potential for expansion is clear in terms of the demand side (also factoring in the potential for uptake in schools). However, the potential for scale-up of current production and processing operations to reach approximately 1,000 producers is an open question.

\section{Home-Grown School Feeding}

School feeding is a simple idea; in practice, however, it is a complex intervention with many possible goals and implementation configurations, involving a broad range of activities by different stakeholders at different levels across the food value chain. In terms of implementation, no one size fits all and different approaches can even coexist within the same country (Gelli and Suwa 2014). HGSF, by providing an institutional market, has the potential to link the increased demand for school feeding goods and services to community-based stakeholders, including smallholder farmers (Sumberg and Sabates-Wheeler 2011). This section is based on the program theory as captured in the design of impact evaluations of alternative HGSF approaches currently underway in Mali and Ghana (Masset and Gelli 2013).

\section{Needs and Target Groups}

The needs for HGSF programs are multidimensional, generally poverty focused, and include:

- Education: Low access and participation (low enrollment or attendance), challenges in learning and cognition (attention, motivation, IQ, high repetition or drop-out).

- Nutrition and health: Short-term hunger, micronutrient deficiencies, unhealthy diets, and nutrition practices.

- Agriculture: Low market access for smallholder farmers.

HGSF can reach different target groups: school- and preschool-aged children eating the school food and their respective households; smallholder farmers involved in food production; and other actors (mostly community groups) within the supply chain involved in food preparation and other incomegenerating activities associated with school feeding service provision.

Programs can either target children individually or through schools, where the school becomes the distribution point for the children who are enrolled. In high- and middle-income countries, school meals are generally integrated within social protection programs and provided free to individual children on the basis of vulnerability and well-being proxies. Children not considered at risk would normally pay for the school feeding, though often at subsidized costs. The vast majority of school feeding programs in low-income countries tend to target children living in vulnerable, food-insecure contexts (Bundy et al. 2009). Certain school feeding programs combine both forms of targeting, offering onsite feeding to all pupils in a school within food-insecure areas and providing extra take-home rations to children identified as more at risk than others. There is little evidence to date of explicit targeting of smallholder farmers, except for the recent experience in Brazil, Cote d'Ivoire, and Kenya. 


\section{Goals and Objectives}

HGSF is generally framed as a social protection and poverty reduction program, and can have multiple goals in the following three areas:

- Supporting incomes of recipient households (those consuming food) and farmer households (those providing the food) and other stakeholders involved in the food supply chain

- Improving the health and nutritional status of schoolchildren

- Increasing school access and learning achievement of schoolchildren

\section{Summary of Activities across Food Value Chain}

A key process objective of the food supply chain is to ensure the timely, uninterrupted supply of quality food with links to smallholder farmers. Ensuring the quality and regularity of the food service delivery is complex, however, in terms of food safety, menu composition (balancing nutrient content and costs), and timeliness of the delivery, involving stakeholders at different levels across the whole supply chain. See Figure A.4 for a stylized example, with key steps (labeled 1-5) described below.

\section{Food Production}

In the HGSF integrated farm-to-school model, such as the school feeding program in Cote d'Ivoire (Gelli et al. 2012), special focus is given to the organization of smallholders around schools. In this particular case, this involves women's groups whose children attend the same schools that benefit from the school feeding program (I). The agricultural side of the program includes provision of inputs such as seeds and tools; advice on the establishment of cooperatives (legal support, statute, internal rules and regulations, organization, financial management); training on farming and livestock techniques, livestock health protection (including vaccinations), and sanitation; food conservation and processing; and marketing techniques (2). Extension services are provided by a parastatal entity linked to agriculture ministries. The supply-side support activities are designed to increase productivity and quality, to incrementally meet the school food requirements over a period of four to six years. An alternative sourcing channel is provided by larger suppliers or traders when smallholders cannot meet the demand (3). Traders must be certified service providers by law. The sourcing volume is based on enrollment figures and meal specifications, with smallholders being the preferred option. Commodity prices are set by a central board. Transportation is organized through nationally contracted service providers or organized by community groups. Some stocks are kept at trader level and producer groups. Community contributions to complement government financing are also possible. Oversight is provided by officers from both the Ministry of Education at the school level and the Ministry of Agriculture at the farmer organization level.

\section{Postharvest Supply Chain}

Processing and service delivery are generally outsourced or decentralized to the community level:

- In the outsourced model, contracted service providers (caterers) organize food procurement and processing (4). Caterers store, prepare, and distribute the meals to the schoolchildren. The caterers arrange transportation. The government provides funds based on a fixed payment per meal served.

- In the decentralized, community-based model, the school management committee is tasked with managing the school feeding program (5). In addition, local communities make contributions, such as labor for cooking or fresh vegetables. At the district level a government unit such as the District Education Office in close collaboration with relevant line ministries and partners carry out quarterly monitoring visits at the school level. 
Figure A.4 Stylized food value chain for HGSF with potential impacts across different target groups

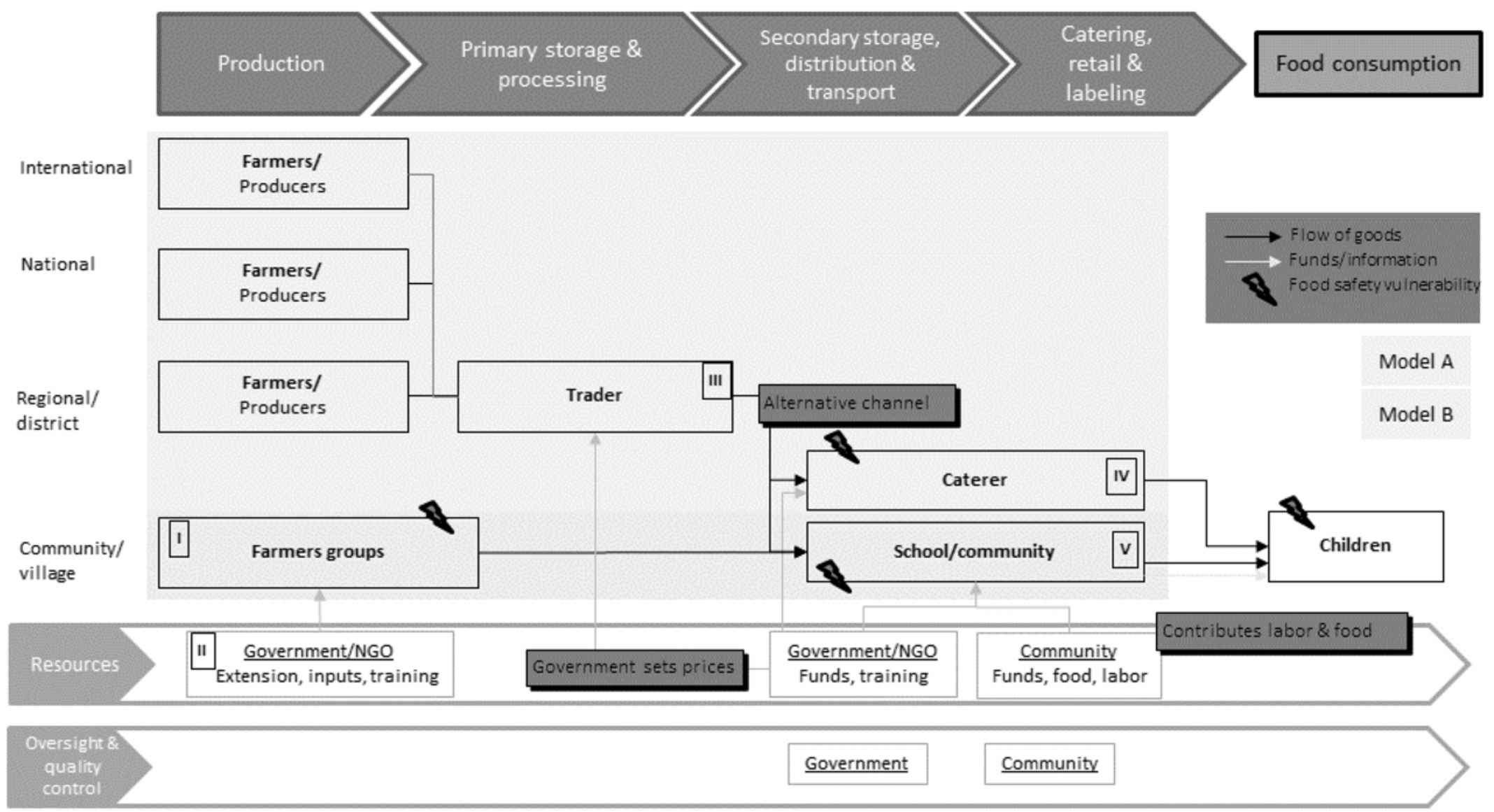

Source: Authors.

Note: $\quad \mathrm{NGO}=$ nongovernmental organization . 


\section{Consumers}

Children consume the food as a meal or snack in school (or in some cases receive a take-home ration). Nutrition and health education are combined with the food service provision in order to promote healthy eating practices at the household level.

\section{Impact Theory}

The impact theory on the educational benefits of school feeding is generally well established (see Alderman and Bundy 2011 for a recent review). School feeding programs can help get children into school and help keep them there, increasing enrollment and reducing absenteeism; and once the children are in school, the programs can contribute to their learning, through avoiding hunger and enhancing cognitive abilities, though the evidence on the latter point is mixed.

HGSF is designed to stimulate the economy by purchasing both food from smallholder farmers and services from other stakeholders in the community. As captured by Masset and Gelli (2013), the program can have three main effects on farmers: output, distribution, and stabilization. Food procurement provides a direct link between producers and the market, directly influencing production investments and diversification, which in turn influence farm output and eventually income. The evidence on these effects is weak and limited to case studies, though two randomized trials are under way.

In terms of nutrition, HGSF programs can influence food consumption through two channels: The first involves the short-term impact on schoolchildren via the delivery of school meals. There is also the opportunity to target age groups with the biggest potential to benefit, including preschoolers or adolescent girls. The level of substitution within households influences overall impact. The second channel is at the household level, where the school provides an entry point for behavior change and communication campaigns aimed at improving health and nutrition, including diet diversification, substitution, and healthy eating practices. Countries in Latin America, most notably Chile and Brazil, have implemented these integrated strategies to tackle the increases in childhood obesity as observed during the nutrition transition (Doak 2002). Evidence on this latter effect is limited.

\section{Sustainability and Scale}

School feeding programs are resource intensive, costing on average \$50 per child per year (Bundy et al. 2009). However, school feeding is active at scale in nearly every country in the world and increasingly integrated within national policies and budgets (WFP 2013). Of the main ideas behind HGSF currently being tested is that by channeling resources through the supply chain into agriculture and community development the intervention can be increasingly sustainable (NEPAD 2005).

\section{Reaching and Engaging End Users with Orange-Fleshed Sweet Potato}

The Reaching End Users (REU) with Orange-Fleshed Sweet Potato proof of concept project disseminated OFSP in Uganda and Mozambique, where vitamin A deficiency is of public health significance. REU was a project led by HarvestPlus as part of A4NH. It was coordinated by the International Center for Tropical Agriculture and the International Food Policy Research Institute (IFPRI). This section is based on the program theory as captured in multiple sources (de Brauw et al. 2013; HarvestPlus 2010).

\section{Needs and Target Groups}

The overall needs for the intervention include:

- Nutrition and health: Vitamin A deficiency. Vitamin A deficiency, in particular, accounts for 6 percent of all deaths of children under five years of age, and 5 percent of the total disease burden of children in this age group, as measured by the DisabilityAdjusted Life Years metric. Globally, 350,000 children become blind each year due to 
vitamin A deficiency (Black et al. 2008), and 66 percent of preschool children in Mozambique and 20 percent in Uganda are deficient in vitamin A (Aguayo et al. 2005; UBOS 2007).

Although the specific targeting criteria differed by country, to maximize the impact the project focused on specific sites where OFSP could be promoted. Potential production areas were assessed based on their high levels of vitamin A deficiency and importance of sweet potato in household diets and farming systems. Other criteria were their proximity and potential to supply to prospective sweet potato markets.

- In Mozambique the project was focused in four districts in Zambezia province, including a total of 36 community organizations in 144 villages. Over the course of the project, 14,000 farming households were targeted.

- In Uganda, the project targeted the districts of Mukono, Kamuli, and Bukedea, including 84 farmer groups. Over the course of the project, 10,000 farming households were targeted.

\section{Goals and Objectives}

The project strategy integrated implementation and learning objectives, including:

- Disseminate orange sweet potato in two countries, Uganda and Mozambique, reaching more than 10,000 farming households in each, using an implementation strategy that includes three integrated components: (1) seed systems, (2) demand creation through behavior change communication, and (3) markets and product development.

- Examine whether such an integrated agriculture-nutrition-market intervention results in improved vitamin A intake among young children and their mothers/female caregivers.

- Analyze alternative dissemination strategies that combined the use of extension personnel linked to community-based promoters for their cost-effectiveness.

- Outline factors key to the success of not only this effort but also to similar endeavors in the future, including seed systems, markets, product development, and demand creation.

\section{Summary of Activities across Food Value Chain}

The REU project design focused on the production, exchange, and consumption of OFSP. It was implemented in Uganda and Mozambique using two different models, which differ primarily in timing and intensity of activities.

\section{Food Production}

The production component involving seed systems and extension had three primary tasks: growing large quantities of OFSP vines for dissemination, distributing vines to farmers, and providing farmers with training on production practices. A tiered implementation structure was designed to streamline vine dissemination, involving NGO extension workers who would train volunteer extension promoters selected from among farmer groups or community groups. These promoters then assisted in vine distribution and trained other group members on how to grow OFSP and maintain the vines between seasons. 


\section{Post-Production Supply Chain}

Project activities included building aggregation and marketing capacity aimed at strengthening the links between farmers and traders. Traders were also trained on the benefits of OFSP and linked to producer groups. Radio commercials and village road signs were also used to sensitize traders to the potential commercial opportunities around OFSP. A range of postharvest storage, processing, and product development activities were also piloted to test vitamin A retention across different supply chains.

\section{Consumers}

The project included a demand creation component that used multiple strategies to train and inform consumers about the nutritional benefits of vitamin A-rich foods, including OFSP. Nutrition promotion messages were conveyed through a variety of sources, including trainings with farmer group members, community theater sessions related to the health benefits of OFSP, radio spots, billboards, and other advertizing. Nutrition promoters were selected from among farmer groups or community groups and were trained to deliver nutrition-related messages to the other members.

\section{Impact Theory}

The REU project aims to reduce vitamin A deficiency through increased OFSP consumption. The primary pathway is through consumption of own production. Because OFSP is a crop not normally grown by the targeted producers, farmers must first learn about and decide to grow the new OFSP varieties, initially through interaction with promoters linked to the agricultural extension program. Other members of the community may later gain access to OFSP, by purchasing vines or receiving them as gifts from other households, or by consuming OFSP obtained in the market or as gifts. Once the OFSP roots are available from fields or markets, households must decide how much OFSP to consume, who will consume it, and in what form. The nutrition promotion activities should affect these behaviors and increase demand for OFSP and other sources of vitamin A. The nutrition trainings also teach households how to store and prepare the crop to maintain high levels of beta-carotene in consumption.

\section{Sustainability and Scale}

REU aims to achieve lasting benefits by introducing a vitamin A-rich variety of a staple crop into smallholder production systems and sensitizing consumers on the health benefits of consumption of foods. The project has directly reached more than 24,000 farmer households in Mozambique and Uganda. 


\section{APPENDIX B: SUPPLEMENTARY FIGURES}

Figure B.1 Examples of entry points across value chains for enhanced nutrition

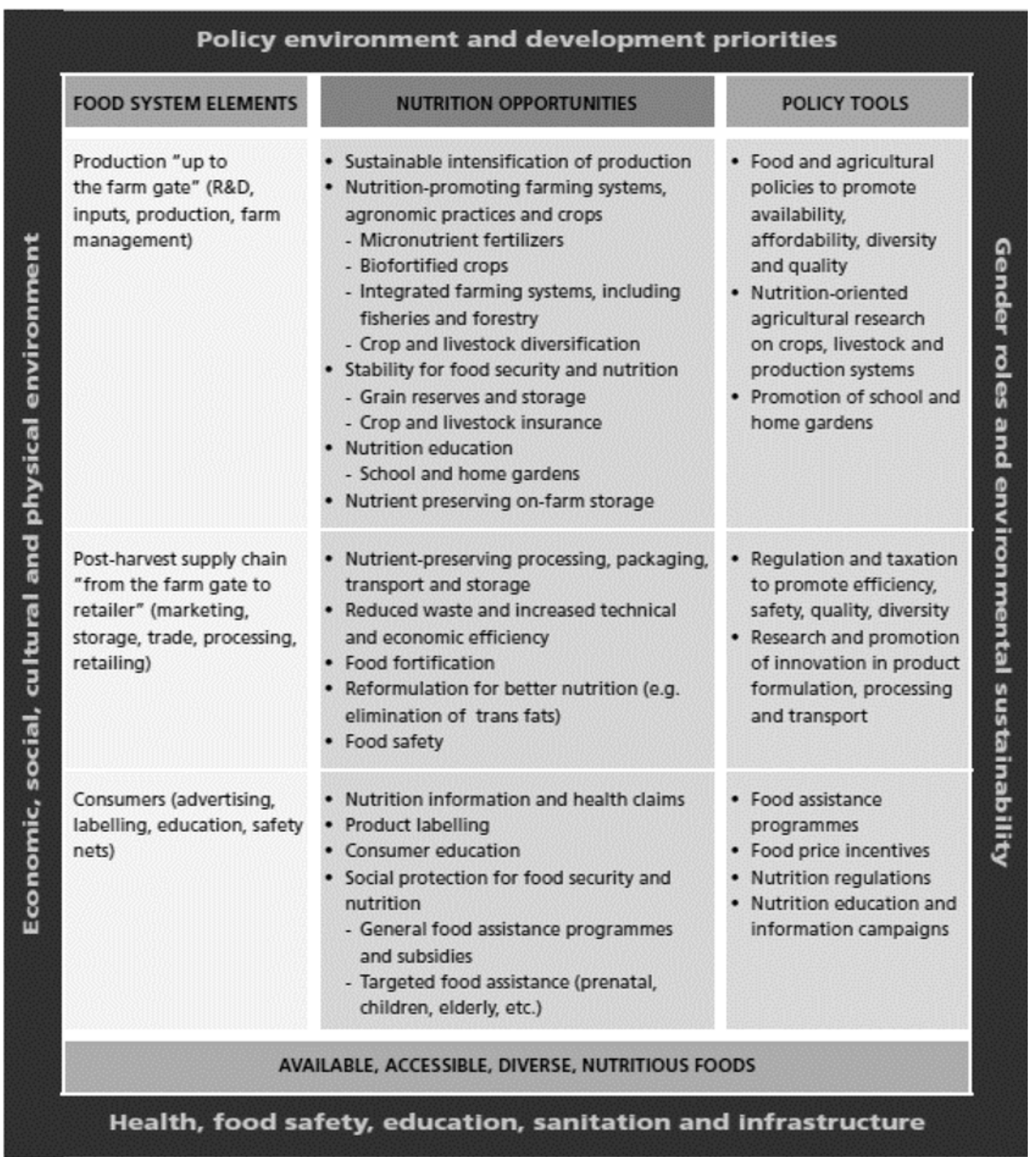

Source: FAO (2013). 


\section{Figure B.2 Example of agriculture and nutrition pathways}

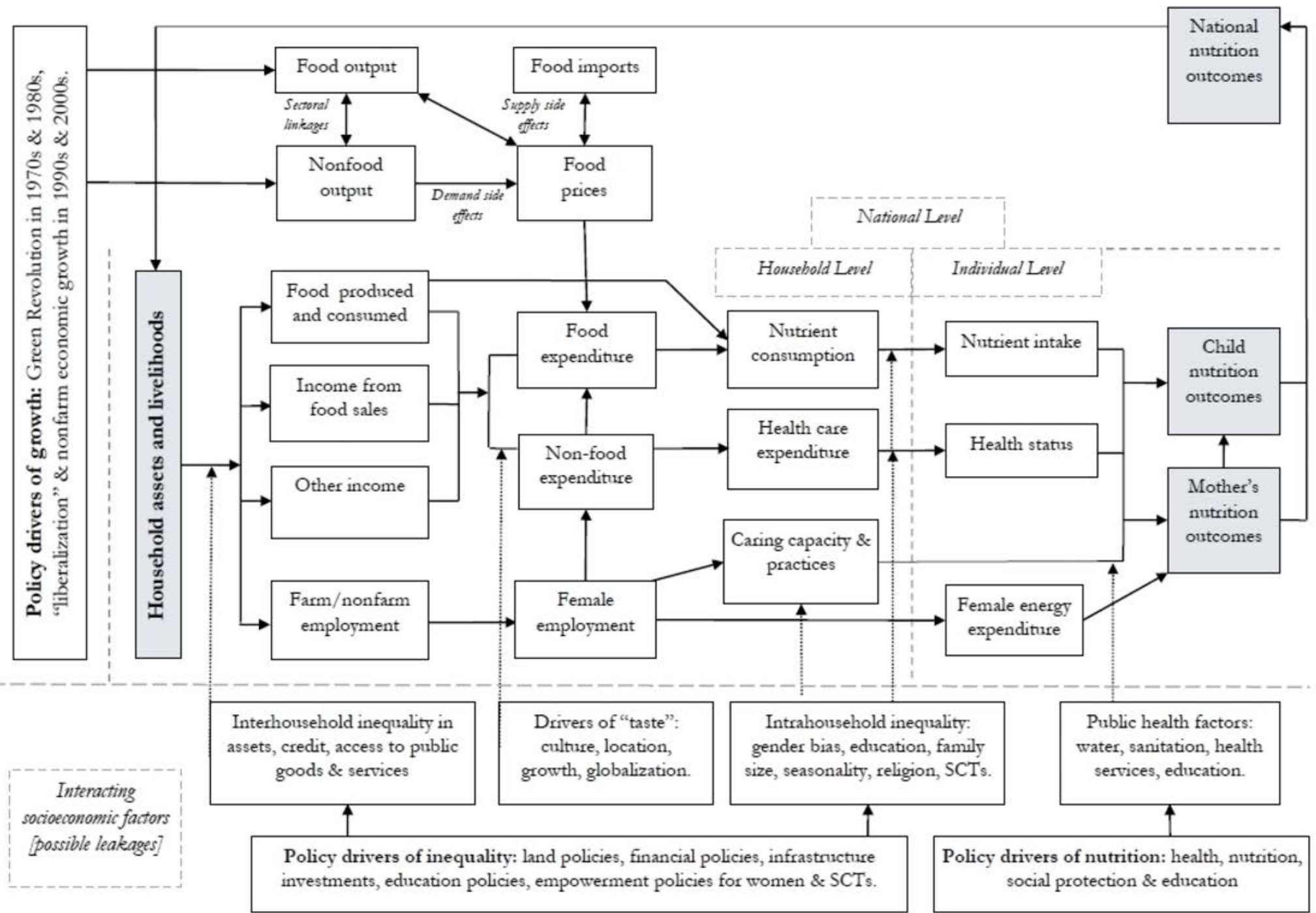

Source: Gillespie et al. (2012)

Note: $\quad$ SCT $=$ social cash transfer. 


\section{REFERENCES}

Aguayo, V. M., S. Kahn, C. Ismael, and S. Meershoek. 2005. "Vitamin A Deficiency and Child Mortality in Mozambique.” Public Health Nutrition 8 (1): 29-31.

Ahmed, A., and M. Sharma. 2007. Home Grown School Feeding Programs to Support Farmers in Africa: Economic Modeling and Supply Response. Project report prepared for the U.N. World Food Programme. Washington, DC: International Food Policy Research Institute.

Alderman H, and D. A. P. 2011. School Feeding Programs and Development: Are We Framing the Question Correctly? World Bank Research Observer. Washington, DC: World Bank.

Alkire, S., R. Meinzen-Dick, A. Peterman, A. R. Quisumbing, G. Seymour, and A. Vaz. The Women's Empowerment in Agriculture Index. 2012. IFPRI Discussion Paper 01240. Washington, DC: International Food Policy Research Institute.

Altenburg, T. 2007. Donor Approaches to Supporting Pro-Poor Value Chains. Report prepared for the Donor Committee for Enterprise Development Working Group on Linkages and Value Chains. Cambridge, UK: Donor Committee for Enterprise Development. www.enterprise-development.org/page/libraryitem?id=386.

Anim-Somuah, H., S. Henson, J. Humphrey, and E. Robinson. 2013a. Policy Guidelines: Enhancing Markets for Nutrient-Dense Foods in Ghana. Evidence Report No. 28. Brighton, UK: Institute of Development Studies.

- 2013b. Strengthening Agri-Food Value Chains for Nutrition: Mapping Value Chains for Nutrient-Dense Foods in Ghana. IDS Evidence Report No. 2. Brighton, UK: Institute of Development Studies.

ANSD (Agence Nationale de la Statistique et de la Démographie) and ICF International. 2012. 2010-11 Senegal Demographic and Health. Calverton, MD, US: ICF International.

Arimond, M., C. Hawkes, M. Ruel, Z. Sifri, P. Berti, J. LeRoy, J. Low, L. Brown, and E. Frongillo. 2011. "Agricultural Interventions and Nutrition: Lessons from the Past and New Evidence.” In Combating Micronutrient Deficiencies: Food-Based Approaches, edited by B. Thompson and L. Amoroso. Rome: Food and Agriculture Organization of the United Nations; Oxfordshire, UK: CABI International.

Arimond, M., D. Wiesmann, E. Becquey, A. Carriquiry, M. C. Daniels, M. Deitchler, N. Fanou-Fogny, M. L. Joseph, G. Kenedy, E. Martin-Prevel, and L. E. Torheim. 2010. "Simple Food Group Diversity Indicators Predict Micronutrient Adequacy of Women's Diets in 5 Diverse, Resource-Poor Settings.” Journal of Nutrition 140 (11): 2059S-69S.

Bacon, C. 2005. "Confronting the Coffee Crisis: Can Fair Trade, Organic, and Specialty Coffees Reduce SmallScale Farmer Vulnerability in Northern Nicaragua?” World Development 33 (3): 497-511.

Black R. E., C. Victora, S. P. Walker, Z. A. Bhutta, P. Christian, M. De Onis, M. Ezzati, S. Grantham-McGregor, J. Katz, R. Martorell, and R. Uauy. 2013. "Maternal and Child Undernutrition and Overweight in Low- and Middle-Income Countries.” The Lancet 382 (9890): 427-451.

Black R. E., L. H. Allen, Z. A. Bhutta, L. E. Caulfield, M. de Onis, M. Ezzati, C. Mathers, J. Rivera. 2008. "Maternal and Child Undernutrition: Global and Regional Exposures and Health Consequences." Maternal and Child Undernutrition Study Group. The Lancet. 371 (9608): 243-260. doi: 10.1016/S01406736(07)61690-0.

Bhutta, Z. A., J. K. Das, R. Arjumand, M. F. Gaffey, N. Walker, S. Horton, P. Webb, a. Lartey, R. E. Black. 2013. "Evidence-Based Interventions for Improvement of Maternal and Child Nutrition: What Can Be Done and at What Cost?” The Lancet 382 (9890): 452-477.

Bundy, D. A. P., C. Burbano, M. Grosh, A. Gelli, M. Jukes, and L. Drake. 2009. Rethinking School Feeding: Social Safety Nets, Child Development, and the Education Sector. Washington, DC: World Bank.

Carletto, C., S. Gourlay, and P. Winters. 2013. From Guesstimates to GPStimates: Land Area Measurement and Implications for Agricultural Analysis. Policy Research Working Paper No. WPS 6550. Washington, DC: World Bank. 
Caldes, N., and A. U. Ahmed. 2004. Food for Education: A Review of Program Impacts. Washington, DC: International Food Policy Research Institute.

De Brauw, A., P. Eozenou, D. Gilligan, N. Kumar, and J. V. Meenakshi. 2012. Biofortification, Crop Adoption and Health Information: Impact Pathways in Mozambique and Uganda. Washington, DC: International Food Policy Research Institute.

De Carvalho, F., B. S. Dom, M. Fiadzigbey, S. Filer, I. Kpekpena, C. Lin, D. Lombardi, L. E. Lopex, V. OwusuNantwi, A. Ramachandran, Y. Tanaka, and S. Tanabe. 2011. Ghana School Feeding Program: Retooling for a Sustainable Future. Accra: Ghana Institute of Management and Public Administration; Berkeley, CA, US: University of California, Berkeley.

Devereux, S., B. Vaitla, and S. Hauenstein-Swan. 2008. Seasons of Hunger: Fighting Cycles of Starvation among the World's Rural Poor. London: Pluto Press in association with Action Against Hunger, ACF International Network.

DIREL (Direction de l’Elevage). 2004. Données Statistiques sur des Productions Animales au Sénégal. Dakar: Ministère de l’Elevage du Sénégal.

Diskin, P. 1999. Agricultural Productivity Indicators Measuremento Guide. Arlington, VA: Food Security and Nutrition Monitoring Project, ISTI, for the U.S. Agency for International Development.

Doak C. 2002. "Large-Scale Interventions and Programmes Addressing Nutrition-Related Chronic Diseases and Obesity: Examples from 14 Countries.” Public Health Nutrition 1 (a): 275-277.

Drewnowski, A. “Concept of a Nutritious Food: Toward a Nutrient Density Score.” American Journal of Clinical Nutrition 200582 (4): 721-732

Epstein, R., L. Henriquez, J. Catalan, G. Weintraub, C. Martinez, F. Espejo. 2004. “A Combinatorial Auction Improves School Meals in Chile: A Case of OR in Developing Countries.” International Transactions in Operational Research 11: 593-612.

FANTA (Food and Nutrition Technical Assistance). 2007. Working Group on Infant and Young Child Feeding Indicators. Developing and Validating Simple Indicators of Dietary Quality of Infants and Young Children in Developing Countries: Additional Analysis of 10 Data Sets. Washington, DC.

FAO (Food and Agriculture Organization of the United Nations). 2011. Rural Households' Livelihood and WellBeing Statistics on Rural Development and Agriculture Household Income. Rome. 2013. State of Food Insecurity in the World. Rome.

Ferguson, E. L., N. Darmon, A. Briend, and I. M. Premachandra. 2004. "Food-based Dietary Guidelines Can Be Developed and Tested Using Linear Programming Analysis.” Journal of Nutrition 134 (4):951-957.

Garrett, J., and M. Natalicchio. 2012. Working Multisectorally in Nutrition: Principles and Practice from Senegal and Colombia. IFPRI Research Monograph. Washington, DC.

Gelli, A., A. Cavallero, L. Minervini, M. Mirabile, L. Molinas, and M. R. de la Mothe. 2011. "New Benchmarks for Costs and Cost-Efficiency of School-Based Feeding Programs in Food-Insecure Areas." Food and Nutrition Bulletin 32 (4): 324-32.

Gelli, A., A. Kretschmer, L. Molinas, and M. R. de la Mothe. 2013. A Comparison of Supply Chains for School Food: Exploring Operational Trade-Offs Across Implementation Models. London: Partnership for Child Development.

Gereffi, G., J. Lee, and M. Christian. 2009. "US-Based Food and Agricultural Value Chains and Their Relevance to Healthy Diets.” Journal of Hunger and Environmental Nutrition 4: 357-74.

Gibson R. S., and E. L. Ferguson. 2008. An Interactive 24-Hour Recall for Assessing the Adequacy of Iron and Zinc Intakes in Developing Countries. HarvestPlus Technical Manual 8. Washington, DC: HarvestPlus.

Gillespie, S., L. Harris, and S. Kadiyala. 2012. The Agriculture-Nutrition Disconnect in India: What Do We Know? IFPRI Discussion Paper 01187. Washington, DC: International Food Policy Research Institute. 
Gómez, M., C. Barrett, L. Buck, H. De Groote, S. Ferris, O. Gao, E. McCullough, D. D. Miller, H. Outhred, A. N. Pell, T. Reardon, M. Retnanestri, R. Ruben, P. Struebi, J. Swinnen, M. A. Touesnard, K. Weinberger, J. D. H. Keatinge, M. B. Milstein, and R. Y. Yang. 2011. "Research Principles for Developing Country Food Value Chains.” Science 332 (6034): 1154-5.

Gómez, M., and K. D. Ricketts. 2013. "Food Value Chain Transformations in Developing Countries: Selected Hypotheses on Nutritional Implications.” Food Policy 42: 139-50.

Habicht J. P., C. G. Victora, and J. P. Vaughan. 1999. Evaluation Designs for Adequacy, Plausibility and Probability of Public Health Programme Performance and Impact. International Journal of Epidemiology 28 (1): 1018. doi:10.1093/ije/28.1.10.

Haddad, L., H. Alderman, S. Appleton, L. Song, and Y. Yohannes. 2003. "Reducing Child Malnutrition: How Far Does Income Growth Take Us?” World Bank Economic Review 17 (1): 107-31.

Hanson, P., S. Ahmad, M. Lin, R. Y. Yang, G. Luther, S. Ramasamy, S. Kumar, J. F. Wang, and V. Afari-Sefa. 2012. Overview of the USAID Horticulture Project. Dhaka: USAID.

Harris, J, and Drimie, S. 2012. Toward an Integrated Approach for Addressing Malnutrition in Zambia: A Literature Review and Institutional Analysis. IFPRI Discussion Paper 01200. Washington, DC.

Hattersley, L. 2012. “Agri-Food System Transformation and Diet-Related Chronic Disease in Australia: A Nutrition-Oriented Value Chain Approach.” Agriculture and Human Values 30 (2): 299-309.

Hawkes, C. 2013. “Applying Food Supply and Value-Chain Concepts for Achieving Positive Nutrition Outcomes.” Presentation at the Meeting of the Minds on Nutrition Impact of Food Systems, Geneva, March 25-28.

Hawkes, C., and M. Ruel. 2011. "Value Chains for Nutrition. 2020 Conference: Leveraging Agriculture for Improving Nutrition and Health.” 2020 Conference Paper 4. Washington, DC: International Food Policy Research Institute.

Hawkes, C., S. Friel, T. Lobstein, and T. Lang. 2012. "Linking Agricultural Policies with Obesity and Noncommunicable Diseases: A New Perspective for a Globalizing World.” Food Policy 37: 343-53.

Henson, S. 2013. “Understanding How Value Chains Create Food System Outcomes: Bangladesh.” Presentation at the A4NH workshop. June 2013. Washington, DC.

Henson, S., J. Humphrey, and B. McClafferty. 2013. Nutritious Agriculture by Design: A Tool for Program Planning. GAIN-IDS Discussion Paper. Washington, DC: Global Alliance for Improved Nutrition.

Hedrick V. E., A. M. Dietrich, P. A. Estabrooks, J. SavlaJ, E. Serrano, and B. M. Davy. 2012. “Dietary Biomarkers: Advances, Limitations and Future Directions.” Nutrition Journal 11: 109. doi: 10.1186/1475-2891-11-109.

Hobbs, J., A. Cooney, and M. Fulton. 2000. Value Chains in the Agri-Food Sector: What Are They? How Do They Work? Are They for Me? Working paper. Saskatchewan, Canada: University of Saskatchewan.

Humphrey, J., and O. Memedovic. 2006. Global Value Chains in the Agrifood Sector. Vienna: United Nations Industrial Development Organization.

Humphrey, J., and L. Navas-Alemán. 2010. Value Chains, Donor Interventions and Poverty Reduction: A Review of Donor Practice. IDS Research Report No. 63. Brighton, UK: Institute of Development Studies.

IPG- IG (International Policy Centre for Inclusive Growth). 2013. United Nations Development Programme. Structured Demand and Smallholder Farmers in Brazil: the Case of PAA and PNAE. Brasilia.

LCIRAH (Leverhulme Centre for Integrative Research on Agriculture and Health) and N-CRSP (USAID’s Nutrition Collaborative Research Support Programme). 2012. "Integrating Agriculture and Nutrition Actions to Improve Maternal and Child Nutrition: Research on Program Impact Pathways.” Report of an LCIRAH/NCRSP workshop, London, June 28-29.

Maestre, M., E. Robinson, J. Humphrey, and S. Henson. 2014. The Role of Businesses in Providing Nutrient-Rich Foods for the Poor: A Case Study in Tanzania. IDS Evidence Report No. 52. Brighton, UK: Institute of Development Studies. 
Masset, E., and A. Gelli. 2013. "Community Participation and the Links Between Agriculture, Nutrition and Education: Design of a Randomised Field Experiment of 'Home-Grown' School Feeding In Mali.” Trials 14: 55.

Maillot, M.; E. L. Ferguson, A. Drewnowski, and N. Darmon. 2008. "Nutrient Profiling Can Help Identify Foods of Good Nutritional Quality for their Price: A Validation Study With Linear Programming. Journal of Nutrition 138 (6): 1107-1113.

Masset, E., L. Haddad, A. Cornelius, and J. Isaza-Castro. 2011. "Effectiveness of Agricultural Interventions That Aim to Improve Nutritional Status of Children: A Systematic Review.” British Medical Journal 344: d8222.

Minot, N. 2014. “Value Chains for Nutrition: Market Environment and Chain Performance.” Presentation at the workshop on Developing a Theory Based Framework to Support the M\&E of Value Chains for Nutrition. IFPRI, Washington, DC. March 17.

NEPAD (New Partnership for Africa’s Development). 2003. The NEPAD Home-Grown School Feeding Programme: A Concept Note. Johannesburg.

NIPORT (National Institute of Population Research and Training), Mitra and Associates, and ICF International. 2013. Bangladesh Demographic and Health Survey 2011. Dhaka: NIPORT; Calverton, MD, US: Mitra and Associates and ICF International.

Padulosi, S. Amaya, K. Jäger, M. Gotor, E. Rojas, W. Valdivia, R. 2014. “A Holistic Approach to Enhance the Use of Neglected and Underutilized Species: The Case of Andean Grains in Bolivia and Peru.” Sustainability 6: 1283-1312.

Porter, M. E. 1985. The Competitive Advantage: Creating and Sustaining Superior Performance. NY: Free Press.

Timmer C. P., W. P. Falcon, and S. R. Pearson. 1984. Food Policy Analysis. Baltimore: Johns Hopkins University Press.

Quisumbing, A., R. Meinzen-Dick, T. L. Raney, A. Croppenstedt, J. A. Behrman, and A. Peterman. 2014. Closing the Knowledge Gap on Gender in Agriculture. Netherlands: Springer.

Robinson, E., I. Akinyele, J. Humphrey, and S. Henson. 2014a. Policy Options to Enhance Markets for NutrientDense Foods in Nigeria. Evidence Report No. 66. Brighton, UK: Institute of Development Studies.

Robinson, E., N. Nwuneli, S. Henson, and J. Humphrey. 2014b. Mapping Value Chains for Nutrient-Dense Foods in Nigeria. Evidence Report No. 65. Brighton, UK: Institute of Development Studies.

Rossi, P. H., M. Lipsey, and H. E. Freeman. 2004. Evaluation: A Systematic Approach. London: Sage.

Ruel, M. T. 2003. Operationalizing Dietary Diversity: A Review of Measurement Issues and Research Priorities. Journal of Nutrition 133: 11 3911S-3926S.

Ruel, M. T., H. Alderman, and the Maternal and Child Nutrition Study Group. 2013. “Nutrition-Sensitive Interventions and Programs: How Can They Help to Accelerate Progress in Improving Maternal and Child Nutrition?” The Lancet 382 (9891): 536-551.

Ryckembusch, D., R. Frega, M. B. Da Silva, I. Sanogo, U. Gentilini, N. Grede, L. Brown. 2013. "Enhancing Nutrition: A New Tool for Ex-Ante Comparison of Commodity-Based Vouchers and Food Transfers.” World Development 49: 58-67.

Stevens, G. A., G. M. Singh, Y. Lu, G. Danaei, J. K. Lin, M. M. Finucane. 2012. “National, Regional, and Global Trends in Adult Overweight and Obesity Prevalences.” Population Health Metrics 10: 22. doi:10.1186/1478-7954-10-22.

Stoian, D., J. Donovan, J. Fisk, and M. Muldoon. 2012. "Value Chain Development for Rural Poverty Reduction: A Reality Check and a Warning.” Enterprise Development and Microfinance 23 (1): 54-69.

Turner, R., C. Hawkes, J. Waage, E. Ferguson, F. Haseen, H. Homans, J. Hussein, D. Johnston, D. Marais, G. McNeill, B. Shankar. 2013. “Agriculture for Improved Nutrition: The Current Research Landscape.” Food and Nutrition Bulletin 34 (4): 369-77. 
Sumberg J., and R. Sabates-Wheeler. 2011. "Linking Agricultural Development to School Feeding in Sub-Saharan Africa: Theoretical Perspectives.” Food Policy 36: 341-349.

Swinburn B. A., G. Sacks, K. D. Hall, K. McPherson, D. T. Finegood, M. L. Moodie, S. L. Gortmaker. 2011. The Global Obesity Pandemic: Shaped by Global Drivers and Local Environments. The Lancet 378 (9793): 804-814.

UBOS (Uganda Bureau of Statistics). 2007. “Uganda Demographic and Health Survey 2006.” Calverton, MD, US.

Van Cauwenberghe, E., L. Maes, H. Spittaels, F. J. van Lenthe, J. Brug, J. M. Oppert, I. De Bourdeaudhuij. 2010. "Effectiveness of School-Based Interventions in Europe to Promote Healthy Nutrition in Children and Adolescents: Systematic Review of Published and ‘Grey’ Literature.” British Journal of Nutrition 103 (6): 781-797.

Webb, P. 2013. Impact Pathways from Agricultural Research to Improved Nutrition and Health: Literature Analysis and Research Priorities. Rome: Food and Agriculture Organization.

Weinberger, K., and T. A. Lumpkin. 2007. "Diversification into Horticulture and Poverty Reduction: A Research Agenda.” World Development 35 (8): 1464-80.

WFP (World Food Programme). 2013. State of School Feeding Worldwide. Rome.

WHO (World Health Organisation). 1995. Physical Status: The Use and Interpretation of Anthropometry. Geneva.

_ 2010. Indicators for Assessing Infant and Young Child Feeding Practices. Geneva.

. 2013. Guiding Principles and Framework Manual for the Development or Adaptation of Nutrient Profile Models. Geneva.

WHO Multicentre Growth Reference Study Group. 2006. WHO Child Growth Standards: Length/Height-For-Age, Weight-For-Age, Weight-For-Length, Weight-For-Height and Body Mass Index-For-Age: Methods and Development. Geneva.

World Bank. 2007. Moving Toward Competitiveness: A Value Chain Approach. Washington, DC.

Yang, R. Y. 2013. The Seed Grant Case Study: Enhanced Nutritional Outcomes of Populations Through NutritionSensitive Agricultural Promotion by a Vegetable Seed Company in Bangladesh and Possible Expansion. Dhaka: USAID. 





\section{RECENT IFPRI DISCUSSION PAPERS}

\section{For earlier discussion papers, please go to www.ifpri.org/pubs/pubs.htm\#dp. All discussion papers can be downloaded free of charge.}

1412. Climate change adaptation assets and group-based approaches: Gendered perceptions from Bangladesh, Ethiopia, Mali, and Kenya. Noora Aberman, Snigdha Ali, Julia A. Behrman, Elizabeth Bryan, Peter Davis, Aiveen Donnelly, Violet Gathaara, Daouda Kone, Teresiah Nganga, Jane Ngugi, Barrack Okoba, and Carla Roncoli, 2015.

1411. Information networks among women and men and the demand for an agricultural technology in India. Nicholas Magnan, David J. Spielman, Kajal Gulati, and Travis J. Lybbert, 2015.

1410. Measurement of agricultural productivity in Africa South of the Sahara: A spatial typology application. Bingxin Yu and Zhe Guo, 2015.

1409. Eliciting farmers' valuation for abiotic stress-tolerant rice in India. Anchal Arora, Sangeeta Bansal, and Patrick S. Ward, 2015.

1408. Understanding the policy landscape for climate change adaptation: A cross-country comparison using the net-map method. Noora Aberman, Regina Birner, Eric Haglund, Marther Ngigi, Snigdha Ali, Barrack Okoba, Daouda Koné, Tekie Alemu, 2015.

1407. Evolving public expenditure in Chinese agriculture definition, pattern, composition, and mechanism. Bingxin Yu, Kevin Chen, Yumei Zhang, and Haisen Zhang, 2014.

1406. Fertility, agricultural labor supply, and production. Bjorn Van Campenhout, 2014.

1405. Impact simulation of ECOWAS rice self-sufficiency policy. Ismaël Fofana, Anatole Goundan, and Léa Vicky Magne Domgho, 2014.

1404. Political economy of state interventions in the Bangladesh food-grain sector. Nurul Islam, 2014.

1403. Loan demand and rationing among small-scale farmers in Nigeria. Aderibigbe S. Olomola and Kwabena GyimahBrempong, 2014.

1402. Revisiting the labor demand curve: The wage effects of immigration and women's entry into the US labor force, 19602010. Alan de Brauw and Joseph R. D. Russell, 2014.

1401. Improving the food policy process: lessons from capacity strengthening of parliamentarians in Ghana. Jagdeep S. Chhokar, Suresh Chandra Babu, and Shashidhara Kolavalli, 2014.

1400. Business operations of agrodealers and their participation in the loan market in Nigeria. Aderibigbe S. Olomola, 2014.

1399. Irrigation Potential in Nigeria: Some Perspectives Based on Factor Endowments, Tropical Nature, and Patterns in Favorable Areas. Hiroyuki Takeshima and Margaret Adesugba, 2014.

1398. Droughts, distress, and policies for drought proofing agriculture in Bihar, India. Avinash Kishore, Pramod Kumar Joshi, and Divya Pandey, 2014.

1397. Aligning public expenditure for agricultural development priorities under rapid transformation: The case of China. Bingxin Yu, Kevin Chen, and Haisen Zhang, 2014.

1396. Public account and coding system in Kenya: The trend and pattern of agricultural expenditure. Bingxin Yu and Haisen Zhang, 2014.

1395. Analysis of agricultural public expenditures in Nigeria: Examination at the federal, state, and local government levels. Aderibigbe Olomola, Tewodaj Mogues, Tolulope Olofinbiyi, Chinedum Nwoko, Edet Udoh, Reuben Alabi, Justice Onu, Sileshi Woldeyohannes, 2014.

1394. International rice trade and security stocks: Prospects for an expanded Asian international rice reserve. Paul A. Dorosh and Abigail Childs, 2014.

1393. The US agricultural act of 2014: Overview and analysis. Carl Zulauf and David Orden, 2014.

1392. The changing landscape of agriculture in Ghana: Drivers of farm mechanization and its impacts on cropland expansion and intensification. Nazaire Houssou and Antony Chapoto, 2014.

1391. Beyond agriculture versus nonagriculture: Decomposing sectoral growth-poverty linkages in five African countries. Paul Dorosh and James Thurlow, 2014. 


\section{INTERNATIONAL FOOD POLICY}

RESEARCH INSTITUTE

\section{www.ifpri.org}

\section{IFPRI HEADQUARTERS}

2033 K Street, NW

Washington, DC 20006-1002 USA

Tel.: +1-202-862-5600

Fax: +1-202-467-4439

Email: ifpri@cgiar.org 